\title{
Updated Perspectives on the Challenges of Managing Multiple Sclerosis During Pregnancy
}

\author{
Ramón Villaverde-González (D) \\ Department of Neurology, Hospital \\ General Universitario José María Morales \\ Meseguer, Murcia, Spain
}

\begin{abstract}
Multiple sclerosis (MS) is a chronic immune-mediated, inflammatory, and degenerative disease that is up to three times more frequent in young women. MS does not alter fertility and has no impact on fetal development, the course of pregnancy, or childbirth. The Pregnancy in Multiple Sclerosis Study in 1998 showed that pregnancy, mostly in untreated women, did not adversely affect MS, as disease activity decreased during pregnancy (although it significantly increased in the first trimester postpartum). These findings, together with the limited information available on the potential risks of fetal exposure to disease modifying treatments (DMTs), meant that women were advised to delay the onset of DMTs, stop them prior to conception, or, in case of unplanned pregnancy, discontinue them when pregnancy was confirmed. Now, many women with MS receive DMTs before pregnancy and, despite being considered a period of MS stability, up to $30 \%$ of patients could relapse in the first trimester postpartum. Factors associated with an increased risk of relapse and disability during pregnancy and postpartum include relapses before and during pregnancy, a greater disability at the time of conception, the occurrence of relapses after DMT cessation before conception, and the use of high-efficacy DMTs before conception, especially natalizumab or fingolimod. Strategies to prevent postpartum activity are needed in some patients, but consensus is lacking regarding the therapeutic strategies for women with MS of a fertile age. This, along with the increasing number of DMTs, means that the decision-making processes in aspects related to family planning and therapeutic strategies before, during, and after pregnancy are increasingly more complex. The purpose of this review is to provide an update on pregnancy-related issues in women with MS, including recommendations for counseling, general management, use of DMTs in pre-pregnancy, pregnancy, and postpartum periods, and breastfeeding-related aspects of DMTs.
\end{abstract}

Keywords: multiple sclerosis, pregnancy, disease modifying treatments, breastfeeding

\section{Plain Language Summary}

Studies in the late 90 s showed that the clinical activity of MS clearly decreases during pregnancy and significantly increases after childbirth, mainly in the first trimester. According to these findings, after the irruption of different treatments with unknown fetal safety, women were advised to delay the onset or discontinue their treatments before conception, as the effects of pregnancy-associated hormones over the immune system could potentially control disease activity. It is now known that in certain circumstances, pregnancy by itself is not able to control the disease. Factors associated with an increased risk of disease activity during pregnancy and after delivery have been identified and several strategies to prevent postpartum reactivation (including, among others, exclusive breastfeeding) have been also proposed. These results, as well as the increasing experience with different MS treatments during early pregnancy and breastfeeding, warrant the application of an individualized approach in women of a fertile age 
with MS; furthermore, different treatment strategies can be applied in women with MS prior to conception, during pregnancy, and postpartum.

\section{Introduction}

Multiple sclerosis (MS) is a chronic immune-mediated, inflammatory, and degenerative disease of the central nervous system that is up to three times more frequent in women than in men, ${ }^{1-3}$ with a female-to-male ratio incidence that has increased over time. ${ }^{4,5}$ The higher prevalence of MS in young women, which can reach 200 cases per 100,000 inhabitants, ${ }^{6,7}$ a delay in childbearing, and the introduction and implementation of new diagnostic criteria $^{8}$ contribute to the increasing proportion of women who become pregnant after an MS diagnosis. Up to $50 \%$ of couples who have not had children before an MS diagnosis have reported wanting to start a family in the future, and up to $25 \%$ of women have been reported to plan a pregnancy in the 2 years following their diagnosis. ${ }^{9}$ It has been estimated that $20-30 \%$ of women with MS will deliver a child after disease onset. ${ }^{9-11}$

In the past, many couples have decided to avoid pregnancy for reasons related to $\mathrm{MS}^{12}$ furthermore, some authors have recently reported lower birth rates than expected in women with $\mathrm{MS}^{13}$ and the proportion of childlessness in women with MS has been reported to be higher than that in age-matched controls. ${ }^{14}$ However, other recent studies have indicated that many women with MS plan to conceive after diagnosis, ${ }^{9}$ which may explain the increase in the prevalence of pregnancy rates in women with MS and a decrease in women without MS. ${ }^{15}$ This seems to reflect a better understanding and greater confidence of patients and neurologists about managing aspects of pregnancy that are related to MS. The annual incidence of pregnancies in a contemporary cohort of women with MS aged between 15 and 45 years was $4.2 \%$, and this incidence reportedly decreases as disability increases. $^{16}$

\section{Sex Differences in MS}

Like other autoimmune diseases, MS is more common in women. In the past six decades, the female-to-male ratio has markedly increased; ${ }^{4,5,17}$ while this phenomenon appears to have stabilized, ${ }^{18}$ this female-to-male ratio has been attributed to changes in lifestyle, environmental exposure, such as sun exposure, vitamin D deficiency, tobacco exposure, and epigenetic factors. ${ }^{19}$ Female patients with MS have higher inflammatory activity and therefore have a higher relapse rate $^{20}$ and more inflammatory lesions, as revealed by magnetic resonance imaging (MRI). ${ }^{21}$ Male patients with MS have more pronounced neurodegeneration, and therefore have a greater risk of disability ${ }^{22-24}$ and cognitive dysfunction, ${ }^{25}$ and reach secondary progressive MS sooner than women. ${ }^{26}$ These sex differences have been explained by genetic differences in immune responses ${ }^{27}$ and direct effects of sex hormones. ${ }^{28}$ These sex-related differences are thought to disappear with menopause; when MS is diagnosed after the age of 50 years, there seem to be no sexrelated differences in its evolution. ${ }^{29}$

\section{Pregnancy and the Risk of MS}

The risk of MS onset appears to decrease during pregnancy. ${ }^{10,30}$ However, some authors have reported that the risk increases after delivery, ${ }^{30-32}$ and others have found no differences in MS onset between the postpartum period and pre-pregnancy period.

Several epidemiological studies have found no association between number of pregnancies and subsequent risk of MS. ${ }^{11,30,33-36}$ On the contrary, other authors have reported that MS risk was higher in nulliparous women, and that it increased with age. ${ }^{10}$ Data from the Danish MS Registry have provided evidence that having children reduces the risk of MS by about $46 \%$ in women (but not in men) in the following 5 years. ${ }^{37}$ Similar findings were reported by Ponsonby et al, who reported a $49 \%$ reduction in the risk of a first clinical attack of MS for each child born. ${ }^{38}$ Recent work found that women with previous pregnancies and childbirths had a median delay of more than 3 years until the first clinical attack of MS compared with those who had never been pregnant. ${ }^{39}$ It remains unclear if this proposed protector effect of pregnancy on MS risk is the result of a temporary immunotolerant state during pregnancy or a bias derived from prodromic symptoms of MS that result in choosing not to have children. ${ }^{40,41}$ That said, in female patients with radiologically isolated syndrome, pregnancy has been associated with a shorter time of conversion to the first neurological event; ${ }^{42}$ however, it is likely that the immunological process has already started in radiologically isolated syndrome, and postpartum reactivation could explain these results.

\section{Effects of MS on Fertility, Pregnancy, and Childbirth}

Although endocrinological changes ${ }^{43,44}$ that are more pronounced with greater disease activity ${ }^{45}$ have been reported 
in women with MS, there is now a wide consensus that MS does not significantly alter fertility and has no impact on fetal development, the course of pregnancy, or childbirth. ${ }^{1,14,46-49}$ However, an increase of caesarean sections, assisted delivery, preterm births, and lower birth weights have been reported in women with MS. ${ }^{47,50-54}$ Some authors have also reported a higher risk of adverse delivery outcomes in patients with higher levels of disability. ${ }^{55-57}$ It has been suggested that this is because physicians are more inclined to deliver patients with a presumed higher risk conservatively, rather than reflecting an effect of MS itself. ${ }^{54}$ Conversely, women with MS may have an increased risk of infection during pregnancy, particularly genitourinary and upper respiratory infections. ${ }^{53,58}$

\section{The Impact of Pregnancy on MS Course}

\section{The Impact of Pregnancy on the Short-Term Course of MS}

Most of the current knowledge about the evolution of MS during pregnancy and after delivery has been obtained from the multicenter Pregnancy in Multiple Sclerosis Study, ${ }^{59-61}$ which was the first prospective study to explore the relationship between pregnancy and MS. This study included untreated women with MS, most of whom were in their first pregnancy. It showed a reduction of more than $70 \%$ in the annualized relapse rate (ARR) during pregnancy, which is more than any therapeutic effect reported to date, and a significant ARR increase in the first 3 months postpartum. Thus, the ARR of the 9 months of pregnancy and the first 3 months after delivery combined was the same as the pre-gestational ARR. Numerous subsequent studies ${ }^{62-65}$ and three meta-analyses ${ }^{66-68}$ have confirmed that the risk of relapse is reduced during pregnancy and significantly increases after childbirth, mainly in the first trimester, according to pregnancy and prepregnancy rates. This pattern has also been demonstrated by MRI studies showing a postpartum increase in $\mathrm{T} 2$ and gadolinium-enhanced lesions. ${ }^{69-71}$

Different immunological changes during pregnancy could explain the positive effects of pregnancy on the disease. One leading explanation is the effect of estrogen and progesterone on the $\mathrm{T}$ helper 1 cell 1 and $\mathrm{T}$ helper 2 cell (Th2) balance, which diverts the immune response to a predominant $\mathrm{Th} 2$ response with an increase in antiinflammatory cytokines. ${ }^{28,40,72,73}$ Other mechanisms, such as direct effects on immune cells, ${ }^{74-76}$ changes in the levels of regulatory T cells and natural killer cells, ${ }^{28,71,77-80}$ downregulation of adhesion molecules and metalloproteases, decreased antigenic presentation, and immunotolerance induced by exposure to fetal antigens, ${ }^{73}$ have also been reported. Moreover, neuroprotective and remyelinating properties have been attributed to progesterone. ${ }^{81,82}$ After delivery, there is a reversal of the hormonal changes associated with pregnancy and a sudden return to the immune state prior to pregnancy, causing what has been described as an immune reconstitution inflammatory syndrome-like phenomenon. ${ }^{28}$

Despite being considered a period of disease stability, approximately $15-30 \%$ of patients with MS suffer relapse during pregnancy. ${ }^{56,83-89}$ Factors associated with a greater risk of relapse during pregnancy include the occurrence of relapses the year prior to pregnancy, a greater disability at the time of pregnancy, the appearance of relapses following disease modifying treatment (DMT) cessation before becoming pregnant, an age less than 35 years, and the preconceptional use of high-efficacy DMTs, especially the cell-trafficking blockers natalizumab or fingolimod with longer washout periods. ${ }^{83,88,90-92}$

Up to $30 \%$ of patients relapse in the first 3 months after delivery ${ }^{83,84,87}$ and about $50 \%$ in the first 6 months after delivery, ${ }^{69,84,86,93}$ although more recent population-based studies have suggested that the postpartum relapse risk is lower than this. ${ }^{66,90,94} \mathrm{~A}$ milder MS resulting from the incorporation of new diagnostic criteria that enable an anticipated diagnosis and better pre-pregnancy disease control might contribute to these findings. Postpartum relapses seem to be more severe than relapses prior to pregnancy, ${ }^{95,96}$ and lead to an increased risk of disability. ${ }^{97,98}$ Proposed risk factors for postpartum relapses include the presence of relapses during pregnancy, a greater disability at the time of conception, a greater number of relapses the year prior to pregnancy, the occurrence of relapses after DMT cessation before conception, and the use of high-efficacy DMTs before conception. ${ }^{65,87,88,90,92,94,97-99}$ It also seems that younger patients have a greater risk of relapse 6 months after delivery than do older patients..$^{90,94,100}$

\section{The Impact of Pregnancy on the Long-Term Course of MS}

There is no evidence that pregnancy has a negative impact on the long-term course or progression of MS disability. ${ }^{11,95,101,102}$ In contrast, there is some evidence that pregnancy after MS onset could have a favorable 
long-term effect on the course of MS, as women who deliver one or more children after MS onset appear to have a slower disability progression than nulliparous women with MS. ${ }^{103,104}$ In a recent population-based cohort study, nulliparous women had an earlier age at progressive MS onset, and a pregnancy-dose effect on delaying progressive MS and severe disability was observed. ${ }^{105}$ Whether pregnancy has a true protective effect on the MS course due to transient immunosuppression, or whether it represents a bias derived from female patients with milder MS being more inclined towards childbearing and causing those with more aggressive MS to avoid pregnancy, warrants further investigation. ${ }^{103,104}$

\section{Management of MS During the Pre-Pregnancy Period (Box I)}

Insufficient maternal vitamin D during pregnancy may increase the risk of MS in offspring, ${ }^{106}$ and higher maternal milk and vitamin $\mathrm{D}$ intake during pregnancy has been associated with a lower risk of offspring developing $\mathrm{MS} ;{ }^{107}$ thus, preconception vitamin D supplementation is recommended. Folic acid must be taken before trying to conceive following general guidelines in women who wish to become pregnant. ${ }^{108}$ Women should also avoid alcohol and smoking, and maintain good sleep hygiene and diet. ${ }^{1}$

For most symptomatic treatments used in MS, such as those for urinary disturbances, spasticity, fatigue, or pain, there is limited evidence of their safety and they should not be used during pregnancy; before a planned pregnancy, these treatments should therefore be stopped or used only at minimum doses for the shortest time. ${ }^{109}$ Oral drugs used for the treatment of spasticity-related symptoms (baclofen or tizanidine) and fatigue (modafinil or amantadine) are generally contraindicated during pregnancy and should be discontinued before pregnancy, ${ }^{110-112}$ but intrathecal baclofen seems to be safe. ${ }^{112}$ Fampridine, which is used for improving gait speed in MS, is also contraindicated as experience of use during pregnancy is scarce, albeit without bad outcomes. ${ }^{113}$

Assisted reproduction technology (ART) is frequently used in patients with $\mathrm{MS}$, with a reported use in up to $14 \%{ }^{114}$ and in $29 \%{ }^{115}$ of pregnancies in patients with MS. An increased relapse risk after ART has been described, mostly after unsuccessful cycles in the 3-month period after ART compared to 1 year before ART, and predominantly with gonadotropin-releasing hormone agonists rather than antagonists. ${ }^{48,116-119}$ A recent meta-analysis confirmed an increased ARR 3 months after ART with both gonadotropin-releasing hormone agonists and antagonists, independent of whether cycles were successful or not. ${ }^{120}$ It has been postulated that continuation of DMTs could prevent the increased risk of relapse after ART. ${ }^{120,121}$

\section{Treatment-Naïve Patients}

Women with MS of a childbearing age should be asked about their family plans at or soon after the diagnosis, and physicians must initiate a discussion on pregnancy-related issues, such as the effects of pregnancy on the course of the disease, fetal safety of exposure to DMTs, and DMT exposure while breastfeeding. A recent survey reported that a considerable proportion of patients felt that they did not receive adequate information about the potential teratogenic effects of DMTs. ${ }^{9}$ Family planning should be an essential element when choosing an initial therapy for MS, women must be advised about the safety of DMT use during pregnancy, and a planned pregnancy should be recommended.

Some authors have proposed that some patients with immediate pregnancy plans after an MS diagnosis could defer DMT onset. ${ }^{122}$ However, there are several arguments in favor of starting DMT. Namely, it is widely accepted that early MS treatment prevents long-term disability ${ }^{123,124}$ and the same should apply to women with MS who are planning a pregnancy, which can take up to 7 months. ${ }^{49,92,99}$ Moreover, the presence of relapses in the year prior to pregnancy increases the risk of relapse during pregnancy and after delivery, and stabilization of disease could therefore prevent disease activity during pregnancy and after delivery. Thus, DMT exposure in the pre-conception period might be protective against postpartum relapses, ${ }^{64,99,125}$ and preconception use of low-efficacy DMTs seems to prevent postpartum relapses compared to no DMT use prior to pregnancy. ${ }^{90}$ In conclusion, women who are planning a pregnancy should not delay DMT onset, and it seems reasonable to start a DMT before conception, even in women with milder MS. Clinical and MRI monitoring is recommended before conception, ${ }^{40}$ and reaching disease stability is desirable, with a 1-year relapse-free period prior to conception in normal evolving MS, or even 2 years in highly active MS. ${ }^{109,126,127}$ Patients should be advised about available contraceptive methods during this period. ${ }^{128}$

The choice of treatment should be individualized, taking into consideration prognostic factors, comorbidities, lifestyle, treatment-related risks, patient preferences, and 
Box I General Recommendations Before, During and After Pregnancy

\section{Before pregnancy}

- Ask about family plans at or soon after the diagnosis. Discussion about pregnancy-related issues.

- Consider family planning when choosing an initial therapy.

- Do not delay DMT onset.

- A non-teratogenic DMT is preferable in fertile women. Patients should be advised about available contraceptive methods especially during treatment with sphingosine-I-phosphate-receptor modulators and teriflunomide, and at least 4 months after alemtuzumab, 6 months after cladribine and I month after anti-CD20 therapies.

- A planned pregnancy and a relapse-free period prior to pregnancy are recommended (I year in normal evolving MS and even 2 years in highly active MS).

- Pre-conceptional vitamin $D$ and folic acid supplementation. Avoid alcohol and smoking.

- IFN- $\beta$, GA, DMF and NTZ could be maintained until conception.

- Teriflunomide, fingolimod, siponimod, ozanimod and ponesimod must be stopped before conception (see Table I) and switching to other DMT could be recommended.

\section{During pregnancy}

- If a pregnancy is confirmed in a woman taking potentially teratogenic treatment, immediately discontinue DMT and recommend an ultrasound study.

- DMF must be discontinued immediately when pregnancy is confirmed. IFN- $\beta$ and GA could be administered even throughout the pregnancy. NTZ could be maintained until the 30th-34th gestational week at 6- to 8-week intervals.

- Clinical and laboratory monitoring should continue, including John Cunningham virus serology in women treated with natalizumab and monthly blood and urine tests in those treated with alemtuzumab in the previous years.

- Advise that urinary tract infections are more frequent during pregnancy and recommend pelvic floor exercises.

- Apply standard protocols of blood pressure and glycemic control.

- Continue vitamin D and folic acid supplementation.

- If necessary, an MRI without gadolinium could be obtained.

- In case of a disabling relapse the standard high dose of intravenous methylprednisolone can be used, especially in 2nd and 3rd trimesters.

- In all cases of DMT or corticosteroids fetal exposure, consider an organ screening ultrasound at 20-22 weeks of gestation.

- In the 3rd trimester a visit should be programmed to update the neurological status and plan the postpartum period.

- Exclusive breastfeeding should be encouraged whenever possible.

- Advise that the choice of the type of anesthesia and delivery should be based on obstetric criteria.

- Follow the same vaccination indications as the general pregnant population: Inactivated influenza, inactivated diphtheria, tetanus, and acellular pertussis (Tdap) and mRNA Covid-19 vaccines.

\section{After delivery}

- Patients should be closely monitored during the first trimester postpartum.

- There is no clear evidence to support the use of intravenous corticosteroids or intravenous immunoglobulins to prevent postpartum relapses.

- Resuming DMT soon after delivery, especially high-efficacy therapies in high-risk patients, is associated with a reduced risk of postpartum relapse.

- Breastfeeding does not have a harmful effect for women with MS and must not be contraindicated.

- Exclusive breastfeeding could prevent relapses after childbirth, and it must be recommended unless a DMT contraindicated during lactation is going to be resumed.

- IFN- $\beta$ and GA are considered safe during lactation.

- Intravenous methylprednisolone to treat postpartum relapses is not contraindicated. Consider delaying breastfeeding for 2-4 hours after administration to minimize infant exposure.

risk aversion. Given that a high proportion of pregnancies are unplanned ${ }^{9,129}$ and an almost $10 \%$ rate of contraceptive failure has been reported, ${ }^{130}$ even in women without pregnancy intention, an initial non-teratogenic DMT recommendation is preferable in women of a fertile age, and a pregnancy test should be carried out before starting the drug. Teriflunomide, fingolimod, siponimod, ozanimod, and cladribine all have teratogenic effects in animal models ${ }^{109,126,127}$ and should not be initiated in the short term in women trying to conceive.

Based on data available for thousands of instances of first-trimester exposure, first-line immunomodulatory drugs beta interferon (IFN- $\beta$ ) and glatiramer acetate (GA) are now considered safe, and the European Medicines Agency 
(EMA) has withdrawn the contraindication of their use during pregnancy in clinically isolated syndrome and relapsing-remitting MS. These can be maintained until pregnancy is achieved, or even during the entire pregnancy, based on mothers' risk-benefit decision. Reports from large pregnancy registries ${ }^{131,132}$ and manufacturer's postmarketing surveillance studies of subcutaneous IFN- $\beta 1 \mathrm{a},{ }^{133}$ intramuscular IFN- $\beta 1 \mathrm{a},{ }^{134}$ and IFN- $\beta 1 \mathrm{~b}^{135}$ did not find a higher risk of congenital anomalies in newborns exposed to IFN- $\beta$. While some studies have reported that there is an adverse effect of intrauterine exposure to IFN- $\beta$ on birth weight and ${ }^{125,136-139}$ preterm delivery, ${ }^{139,140}$ others have found no such association. ${ }^{63,64,89,141}$ There is sufficient evidence to indicate that exposure to GA is not associated with abortion, premature birth, congenital anomalies, low birthweight, or neonatal size. ${ }^{63,85,125,138,142,143}$ Only a few cases exposed throughout pregnancy to $\mathrm{GA}^{65,144-146}$ or IFN- $\beta^{64,147,148}$ have been reported. There is not enough data to support the use dimethyl fumarate (DMF) during pregnancy. Although harmful fetal effects at high doses have been reported in animals, ${ }^{149}$ in the small number of pregnancies exposed during clinical trials and the postmarketing surveillance program, no increased risk of adverse pregnancy outcomes has been detected. ${ }^{149,150}$ The short half-life of DMF allows its rapid elimination after being discontinued, which would result in only a brief fetal exposure if it is interrupted once pregnancy has been confirmed. However, according to the prescription information, DMF should only be used during pregnancy after weighing up the risks and benefits (Table 1). ${ }^{151,152}$

Women with an aggressive MS onset generally require a high-efficacy therapy and must be advised to delay pregnancy until 1 or 2 years of disease stabilization has been achieved. ${ }^{109}$ If pregnancy is planned in the short term, however, fingolimod and siponimod should not be prescribed because of their teratogenic risk. ${ }^{153,154}$ Natalizumab, which is an IgG4 humanized monoclonal antibody, does not cross the placenta unit until the third month of gestation, ${ }^{155}$ and its use seems to be safe during the first trimester of pregnancy. ${ }^{151,156-161}$ As immune reconstitution therapies, cladribine and alemtuzumab could be attractive alternatives because they can provide long-term disease control once the drug is eliminated, although conception should not be attempted until 4 months after the last dose of alemtuzumab and 6 months after cladribine. ${ }^{162-165}$ Ocrelizumab, which is a humanized anti-CD20 B-cell-depleting IgG1 monoclonal antibody prescribed for relapsing MS and primary progressive MS, actively crosses the placenta after the first trimester ${ }^{166}$ once organogenesis has ended. According to regulatory agencies recommendations, pregnancy should not be attempted until 6 months (US Food and Drug Administration; FDA) or 12 months (EMA) after the last infusion. ${ }^{167,168}$ However, based on its short half-life of 26 days ${ }^{169}$ and its similarities with rituximab, which is a chimeric anti-CD20 monoclonal antibody used off-label in MS, pregnancies could be attempted from 1 month after the last infusion to prevent fetal exposure while retaining the long-lasting preventive effects (Table 1). ${ }^{170}$

\section{Patients Receiving DMTs}

Currently, nearly $80 \%$ of patients with early MS receive DMTs. ${ }^{9,65,171-173}$ This could be explained by the implementation of new diagnostic criteria, the acceptance of early therapeutic interventions in MS and clinically isolated syndrome, ${ }^{122,123,162,174-176}$ and of indefinite treatment in patients even with stable MS, ${ }^{177}$ among others. Furthermore, the delay in childbearing and the fact that nearly $50 \%$ of pregnancies are unplanned ${ }^{62,129,178,179}$ mean that it is increasingly more common for women with MS to start treatment before pregnancy. Consensus is lacking regarding the therapeutic strategies in women with MS undergoing DMT who wish to become pregnant.

Women planning pregnancy have typically been advised to stop their treatments and, in the case of unplanned pregnancy, discontinue treatment when pregnancy was confirmed, except in high-activity disease. ${ }^{52,54,122,170,180-182}$ These recommendations are probably in place because disease activity during pregnancy decreases to a greater degree than it does with classical immunomodulatory drugs, ${ }^{183}$ and the fact that there is limited information about the potential risks of fetal exposure to DMT. The appropriateness of this approach has been supported by reports that the use of DMT 1 year before pregnancy was not associated with a lower risk of postpartum relapses, ${ }^{94}$ and that disease activity in women exposed to DMT at conception versus untreated women was similar during pregnancy ${ }^{64,66}$ and postpartum. ${ }^{94,100}$ Thus, according to recent populationbased studies, the proportion of patients on DMT immediately prior to pregnancy is low, even in highly active MS. ${ }^{58,184}$ However, one possible bias of population-based studies could be that patients with more benign MS decide to stop DMTs before pregnancy, and those with more aggressive MS maintain them. Conversely, other authors have shown that pre-pregnancy use of DMTs could prevent postpartum relapses, ${ }^{64,90,99,125}$ and exposure to IFN- $\beta$ or 
Table I Pregnancy-Related Aspects of Multiple Sclerosis Disease-modifying Therapies

\begin{tabular}{|c|c|c|c|c|}
\hline DMT & $\begin{array}{l}\text { Pre-Pregnancy } \\
\text { Washout }\end{array}$ & Pregnancy & Breastfeeding & Newborn Precautions \\
\hline Beta interferon & Not required & $\begin{array}{l}\text { EMA: May be considered } \\
\text { during pregnancy } \\
\text { FDA: Use only if the benefit } \\
\text { justifies the potential risk to } \\
\text { the fetus. }\end{array}$ & Can be used during breastfeeding & \\
\hline $\begin{array}{l}\text { Glatiramer } \\
\text { acetate }\end{array}$ & Not required & $\begin{array}{l}\text { Use only if the benefit } \\
\text { justifies the potential risk to } \\
\text { the fetus }\end{array}$ & Limited data. Considered safe & \\
\hline Teriflunomide & $\begin{array}{l}\text { Accelerated elimination } \\
\text { procedure until plasma } \\
\text { concentrations are less } \\
\text { than } 0.02 \mathrm{mg} / \mathrm{L}\end{array}$ & $\begin{array}{l}\text { Contraindicated during } \\
\text { pregnancy }\end{array}$ & $\begin{array}{l}\text { Contraindicated during } \\
\text { breastfeeding }\end{array}$ & Risk of birth defects \\
\hline $\begin{array}{l}\text { Dimethyl } \\
\text { fumarate }\end{array}$ & Not required & $\begin{array}{l}\text { Use only if the benefit } \\
\text { justifies the potential risk to } \\
\text { the fetus }\end{array}$ & $\begin{array}{l}\text { Limited data. Risks not excluded. } \\
\text { Use with caution }\end{array}$ & \\
\hline Fingolimod & $\begin{array}{l}2 \text { months (risk of } \\
\text { rebound effect) }\end{array}$ & $\begin{array}{l}\text { Contraindicated during } \\
\text { pregnancy }\end{array}$ & $\begin{array}{l}\text { Contraindicated during } \\
\text { breastfeeding }\end{array}$ & $\begin{array}{l}\text { Risk of fetal loss and birth } \\
\text { defects in animal models }\end{array}$ \\
\hline Siponimod & 10 days & $\begin{array}{l}\text { Contraindicated during } \\
\text { pregnancy }\end{array}$ & $\begin{array}{l}\text { Contraindicated during } \\
\text { breastfeeding }\end{array}$ & $\begin{array}{l}\text { Risk of fetal loss and birth } \\
\text { defects in animal models }\end{array}$ \\
\hline Ozanimod & 3 months & $\begin{array}{l}\text { Contraindicated during } \\
\text { pregnancy }\end{array}$ & $\begin{array}{l}\text { Contraindicated during } \\
\text { breastfeeding }\end{array}$ & $\begin{array}{l}\text { Risk of fetal loss and birth } \\
\text { defects in animal models }\end{array}$ \\
\hline Natalizumab & $\begin{array}{l}\text { Not required (risk of } \\
\text { rebound effect) }\end{array}$ & $\begin{array}{l}\text { Use only if the benefit } \\
\text { justifies the potential risk to } \\
\text { the fetus at least until first } \\
\text { trimester or } 30-34 \text { weeks }\end{array}$ & $\begin{array}{l}\text { EMA: Contraindicated during } \\
\text { breastfeeding } \\
\text { FDA: Use only if the benefit justifies } \\
\text { the potential risk to the infant }\end{array}$ & $\begin{array}{l}\text { Risk of hematological } \\
\text { abnormalities in infants } \\
\text { exposed in the third } \\
\text { trimester }\end{array}$ \\
\hline Alemtuzumab & $\begin{array}{l}4 \text { months after last } \\
\text { dose }\end{array}$ & $\begin{array}{l}\text { Use only if the benefit } \\
\text { justifies the potential risk to } \\
\text { the fetus }\end{array}$ & $\begin{array}{l}\text { EMA: Discontinue during each } \\
\text { course and for } 4 \text { months following } \\
\text { the last infusion. Benefits may } \\
\text { outweigh the risks for the infant } \\
\text { FDA: Discontinue either } \\
\text { alemtuzumab or breastfeeding }\end{array}$ & $\begin{array}{l}\text { Untreated maternal } \\
\text { hypothyroidism increases } \\
\text { the risk for miscarriage and } \\
\text { may have effects on the } \\
\text { fetus. } \\
\text { Risk of neonatal Graves' } \\
\text { disease in mothers with } \\
\text { Graves' disease }\end{array}$ \\
\hline Ocrelizumab & $\begin{array}{l}\text { EMA: } 12 \text { months } \\
\text { FDA: } 6 \text { months }\end{array}$ & $\begin{array}{l}\text { Use only if the benefit } \\
\text { justifies the potential risk to } \\
\text { the fetus }\end{array}$ & $\begin{array}{l}\text { EMA: Contraindicated during } \\
\text { breastfeeding } \\
\text { FDA: Use only if benefit justifies the } \\
\text { potential risk to the infant }\end{array}$ & $\begin{array}{l}\text { Risk of B-cell depletion after } \\
\text { intrauterine or breast milk } \\
\text { exposure }\end{array}$ \\
\hline
\end{tabular}

(Continued) 
Table I (Continued).

\begin{tabular}{|l|l|l|l|l|}
\hline DMT & \multicolumn{1}{|c|}{$\begin{array}{c}\text { Pre-Pregnancy } \\
\text { Washout }\end{array}$} & \multicolumn{1}{|c|}{ Pregnancy } & \multicolumn{1}{|c|}{ Breastfeeding } & Newborn Precautions \\
\hline Cladribine & $\begin{array}{l}6 \text { months after last } \\
\text { dose }\end{array}$ & $\begin{array}{l}\text { Contraindicated during } \\
\text { pregnancy }\end{array}$ & $\begin{array}{l}\text { Breastfeeding contraindicated } \\
\text { during treatment and for I week } \\
\text { after the last dose }\end{array}$ & Risk of congenital anomalies \\
\hline Ofatumumab & $\begin{array}{l}\text { 271 } \\
\text { dose }\end{array}$ & $\begin{array}{l}\text { Use only if the benefit } \\
\text { justifies the potential risk to } \\
\text { the fetus }\end{array}$ & $\begin{array}{l}\text { Use only if benefit justifies the } \\
\text { potential risk to the infant. }\end{array}$ & $\begin{array}{l}\text { Risk of B-cell depletion after } \\
\text { intrauterine or breast milk } \\
\text { exposure }\end{array}$ \\
\hline Ponesimod & I week after last dose & $\begin{array}{l}\text { Contraindicated during } \\
\text { pregnancy }\end{array}$ & $\begin{array}{l}\text { Contraindicated during } \\
\text { breastfeeding }\end{array}$ & $\begin{array}{l}\text { Risk of fetal loss and birth } \\
\text { defects in animal models }\end{array}$ \\
\hline
\end{tabular}

Abbreviations: DMT, disease-modifying therapy; EMA, European Medicines Agency; FDA, United States Food and Drug Administration.

GA during the first weeks of pregnancy could prevent relapses during pregnancy and after delivery. ${ }^{85,89}$ Furthermore, it has been consistently reported that discontinuation of cell-trafficking blockers fingolimod or natalizumab, especially with long washout periods, is associated with a high risk of relapse and disability progression prior to conception, during pregnancy, and postpartum, ${ }^{88,91,157,171,185}$ as well as with radiological activity. ${ }^{186}$ Even the discontinuation of low-efficacy DMTs in the case of planned pregnancy has been reported to result in an increase in relapse activity before conception. $^{92}$

In the past 5 to 10 years, an increasing trend in the proportion of pregnancies conceived on therapy has been observed, ${ }^{16,90}$ which is likely to reflect a greater confidence in the safety of DMT use during the first weeks of pregnancy and an awareness of the risks of treatment discontinuation in highly active MS.

First-line therapies (Table 1): Patients taking IFN- $\beta$ or GA can continue treatment until conception (see above). Patients on teriflunomide must perform an accelerated elimination procedure with cholestyramine or activated charcoal for 11 days prior to attempting conception, and contraception should be recommended until plasma concentrations of teriflunomide are less than $0.02 \mathrm{mg} / \mathrm{L} .{ }^{187}$ Switching to IFN- $\beta$ or GA could be indicated after teriflunomide elimination and, in that case, a period of observation must be performed to assess disease stabilization. The short half-life of DMF allows its rapid elimination after being discontinued, such that it can be maintained until conception, resulting in only a brief fetal exposure. However, DMF should only be used during pregnancy after weighing up the risks and benefits, and if risks are not accepted, a switch to IFN- $\beta$ or GA should be considered.

High-efficacy or second-line DMTs (Table 1): Fingolimod is contraindicated during pregnancy and must be stopped at least 2 months before conception. A marked increase in clinical and radiological activity before and during pregnancy has been reported after discontinuing fingolimod to become pregnant. ${ }^{91,171}$ In some cases, this reactivation is greater than that of the pre-fingolimod period, which can be considered as a rebound phenomenon. ${ }^{188-192}$ A longer washout period and lymphopenia (less than $300 / \mu \mathrm{L}$ ) in the first 3 months after fingolimod onset have been associated with a greater risk of MS reactivation. ${ }^{88,91,171,188}$ Therefore, switching to immunomodulatory drugs, natalizumab (especially in John Cunningham virus seronegative patients), anti-CD20 monoclonal antibody, cladribine, or alemtuzumab could be optimal, depending on the patient's characteristics and risk acceptance. A period of at least 6 or 12 months to check disease stability is recommended.

Siponimod has a shorter half-life than fingolimod, which allows women to stop the drug 10 days before conception. Disease reactivation has been described after withdrawal from siponimod ${ }^{193}$ and switching to another drug before trying to conceive should probably be recommended. Ozanimod takes about 3 months to be eliminated, so women planning a pregnancy in the short term should stop it at least 3 months before conception, ${ }^{194,195}$ and switching to other DMTs, as with fingolimod, would be reasonable. 
The EMA and FDA have stated that natalizumab should only be used during pregnancy if the potential benefit to the patient justifies the potential risk to the fetus. ${ }^{196,197}$ It has been extensively reported that discontinuing natalizumab before conception can result in a high risk of relapse during pregnancy and postpartum, radiological activity, and disability progression. ${ }^{90,91,157,171,185,198-200}$ Stopping natalizumab prior to pregnancy is associated with rebound relapses and up to $37 \%$ of women who stopped it prior to pregnancy reportedly suffered relapses during pregnancy. ${ }^{157}$ A longer washout period seems to be associated with a greater risk of relapse during pregnancy ${ }^{91,171,201}$ and disability progression. ${ }^{201}$ Given that natalizumab does not cross the placental barrier during the first trimester of pregnancy, no clear adverse pregnancy outcomes have been reported after fetal exposure during the first trimester, and receiving natalizumab after the last menstrual period has been associated with a three-fold reduction of relapse risk during pregnancy; ${ }^{158,160,161}$ thus, this DMT should not be stopped before pregnancy. In women who do not accept any risks and have no immediate pregnancy plans, switching to anti-CD20 depleting antibodies, cladribine, or alemtuzumab could be considered.

Women treated with cladribine or alemtuzumab should attempt pregnancy from 6 months and 4 months, respectively, after the last dose, whereby the long-lasting effects of these treatments can provide long-term disease control once the drug is eliminated without fetal exposure. ${ }^{164,165}$

Although labelling recommendations state that pregnancy should not be attempted until 6 months (FDA) or 12 months (EMA) after the last infusion, ocrelizumab only crosses the placenta after the first trimester. Based on its half-life, women treated 1 month or longer before conception theoretically do not expose their fetus to the drug, yet the long-lasting preventive effects persist. Moreover, its biological effects wear off slowly and cessation is not associated with rebound disease activity. The same considerations could be applied to rituximab, which is frequently used as an off-label treatment in MS. In an observational retrospective cohort study, discontinuing rituximab before pregnancy was found to result in a significantly better control of disease activity during pregnancy and postpartum versus stopping natalizumab. ${ }^{199}$

\section{Management of MS During Pregnancy (Box I)}

During pregnancy, women should ideally be clinically monitored every trimester. Laboratory monitoring should continue during pregnancy, including regular John Cunningham virus serology in women treated with natalizumab and monthly blood and urine tests in women treated with alemtuzumab in the previous years. Alemtuzumab-associated autoimmune disorders, especially thyroid disorders, can severely affect the fetus. If a thyroid disorder is confirmed, woman should be immediately referred to an endocrinologist for the initiation of appropriate thyroid treatment, and monitored during pregnancy in a specialist setting. ${ }^{165,202,203}$ Pregnant women with MS must be advised that urinary tract infections are more frequent during pregnancy, ${ }^{204}$ should be trained to recognize initial urinary tract infection symptoms, and advised to perform pelvic floor exercises. ${ }^{205}$ Standard protocols of blood pressure and glycemic control should also be applied.

Women must continue with folic acid supplements to prevent newborn neural tube defects, as well as with vitamin D supplementation, which, in addition to its immunomodulatory effects, seems to diminish the risk of bad pregnancy outcomes. ${ }^{206}$ If necessary, in case of disease reactivation or safety concerns (such as women at risk of developing progressive multifocal leukoencephalopathy), an MRI without gadolinium can be obtained. ${ }^{205,207}$ According to the results of a large, single-center cohort study, gadolinium is contraindicated during pregnancy unless it is essential to the health of the woman or fetus, as it crosses the placenta and could cause a fibrotic condition in the fetus called nephrogenic systemic fibrosis, stillbirth, or neonatal death. ${ }^{208-210}$

Considering that nearly half of pregnancies are unplanned, ${ }^{62,129,178,179}$ it is not unusual for women on potentially teratogenic DMTs to become pregnant. If pregnancy is confirmed in a woman taking fingolimod, siponimod, ozanimod, teriflunomide, or cladribine, she should be advised to immediately discontinue treatment, and an ultrasound study should be recommended. In the case of teriflunomide, washout with cholestyramine or activated charcoal must be prescribed. Women taking GA or IFN- $\beta$ can stop treatment after positive pregnancy test or maintain it throughout the pregnancy, and this choice generally depends on pre-pregnancy activity and a woman's risk aversion. Women taking DMF should immediately stop it at the time of conception. It has been reported that maintaining natalizumab during the first trimester can reduce the risk of relapse and disability progression during pregnancy compared to discontinuing it at the time of pregnancy, ${ }^{156}$ and a $24.5 \%$ reduction in relapse risk during 
pregnancy per month continued has been demonstrated. ${ }^{90}$ Considering that transient hematological abnormalities have been showed in newborns exposed to natalizumab during the third trimester, ${ }^{211-213}$ some authors recommend maintaining natalizumab during pregnancy up until the 30th-34th gestational week at 6- to 8-week extended intervals. ${ }^{126,127,170,205,212,214} \mathrm{~A}$ reduced dose has also been proposed ${ }^{212}$ to reduce circulating natalizumab levels and therefore reduce fetal exposure. Extended interval dosing of natalizumab has not been associated with a decreased efficacy in MS. ${ }^{215-218}$

There are conflicting data concerning the safety of corticosteroids during pregnancy. In addition to the risk of precipitating gestational diabetes, some studies have reported an increased risk of lower birth weight ${ }^{89,219}$ and malformations, especially cleft palate, ${ }^{220,221}$ that have been questioned in recent publications, ${ }^{222,223}$ and adverse long-term neurodevelopment outcomes have also been reported. ${ }^{224}$ Women who decide to stop DMTs to become pregnant because of the fear of potential risks of fetus exposure should be advised that they could suffer more relapses during pregnancy, and could require more frequent corticosteroid treatment, which are not totally exempt from risks. ${ }^{85,89}$ Methylprednisolone and prednisone are metabolized and inactivated by the placenta, and only a minimal part of the dose reaches the fetus; on the contrary, betamethasone and dexamethasone are minimally metabolized and they should be avoided during pregnancy. ${ }^{225}$ The standard treatment of MS relapses with high doses of methylprednisolone, which are generally 1000 milligrams intravenously daily for 3-5 days, could therefore be used, especially in the second and third trimesters in cases of disabling relapses while avoiding oral tapering. ${ }^{109,205,226}$ Severe steroid-refractory relapses could be treated with therapeutic apheresis. ${ }^{109,205,214}$ The most common complications of plasma exchange or immunoadsorption are hypotension, thromboembolism, coagulopathy, thrombocytopenia and catheter-associated infections, thrombosis, and dislocations. ${ }^{227}$ In the case of rebound relapses after natalizumab or fingolimod cessation, resuming natalizumab or starting anti-CD20 depleting monoclonal antibodies have been proposed. ${ }^{170}$ In all cases of DMT or corticosteroids fetal exposure, an organ screening ultrasound should be considered at 20-22 weeks of gestation.

In the third trimester, a visit should be programmed to make an updated report of the neurological status and plan the postpartum period. Exclusive breastfeeding should be encouraged whenever possible. Women must be advised that MS does not contraindicate any type of obstetric anesthesia, and that epidural analgesia can be safely performed. There is no negative effect of obstetric anesthesia on postpartum relapses or disability progression, ${ }^{54}$ and the choice of the type of anesthesia and delivery should be based on obstetric criteria.

Pregnant women with MS have the same vaccination indications as the general pregnant population (only live vaccines are contraindicated due to the theoretical risk to the fetus), and so should be vaccinated according to local recommendations. Inactivated influenza and the inactivated diphtheria, tetanus, and acellular pertussis (Tdap) are routinely offered to pregnant women with $\mathrm{MS}^{228,229}$ Preliminary findings have shown no obvious safety issues among pregnant women who received an mRNA Covid-19 vaccine, ${ }^{230}$ and since pregnancy itself is associated with an increased risk of severe infection, mRNA Covid-19 vaccines should be recommended and may be administered at the same time as other vaccines routinely administered in pregnancy (eg, influenza, Tdap). A separation period between vaccinations is unnecessary, ${ }^{231}$ although some authors recommend a 7- to 14-day gap between receiving a COVID-19 vaccine and the flu vaccine. ${ }^{232,233}$ Other vaccines may be considered in cases of high risk or specific exposure to certain infectious agents. 228,234

\section{Management of MS After Delivery (Box I)}

After delivery, especially the first trimester postpartum, is a critical period for an increased risk of clinical and radiological activity, during which patients should be closely monitored. In recent years, the risk of postpartum relapses seem to be attenuated ${ }^{66,90,94}$ up to $30 \%,{ }^{66}$ partly due to a statistical effect derived from the diagnosis of milder forms of the disease using the new diagnostic criteria, but perhaps also due to a better management of pregnancyrelated issues; indeed, shorter DMT washout periods ${ }^{91}$ and an increased use of DMT before pregnancy and at the time of conception have been reported in recent work. ${ }^{16,90}$ Although some reports have not found there to be a relationship between the use of DMT before or at the time of conception with the occurrence of relapses during pregnancy or after delivery, ${ }^{66}$ others have found that exposure to DMT before pregnancy or during the first weeks of gestation could decrease the risk of MS activity during pregnancy or postpartum. ${ }^{64,85,89,90,99,125}$

Several predictive factors associated with postpartum relapses have been described, including a higher relapse 
rate and a higher disability score before pregnancy, occurrence of relapses during pregnancy, ${ }^{65,87,90,97-99,235}$ the use of high-efficacy DMT prior to pregnancy, ${ }^{88,90}$ and a younger age at the time of conception. ${ }^{94,100}$ As mentioned before, one of the key aspects in the management of pregnancy in patients with MS is the prevention of relapses and disability postpartum, and some strategies must be applied before and during pregnancy. Proposed strategies include achieving disease stabilization before conception, using DMT prior to pregnancy, exposure to immunomodulatory drugs before or even during first weeks of gestation, and, in patients treated with cell-trafficking blockers (natalizumab or fingolimod), preventing longer washout periods and maintaining natalizumab until the first 1-2 trimesters of pregnancy. ${ }^{64,85,89,91,99,109,125,126,156,157,201}$

Various measures have been proposed to prevent postpartum relapses and disability progression after delivery. Some studies have shown that intravenous immunoglobulins, at different doses and with different administration schedules, both during pregnancy and immediately after delivery, can reduce the risk of postpartum relapse. ${ }^{236-240}$ However, other reports ${ }^{241,242}$ and a recent meta-analysis ${ }^{243}$ have failed to confirm these benefits, and so there is no clear evidence to support the routine use of intravenous immunoglobulins. ${ }^{214}$ Methylprednisolone, 1000 milligrams monthly for 6 months, has been found to be effective in preventing postpartum relapses in a small casecontrol study. ${ }^{244}$ Another study with few patients and different treatment schedules also reported there to be a positive effect of corticosteroids, ${ }^{245}$ but there are no prospective data that support the use of corticosteroids to prevent postpartum relapses. Attempts to control the increase in postpartum activity with hormonal therapy (progesterone and estradiol) have not been shown to be effective. ${ }^{246}$

When resuming DMT soon after delivery, ${ }^{88}$ even DMTs with a slow mechanism of action, such as GA and IFN- $\beta$, are associated with a decrease in postpartum relapse risk, ${ }^{86,235,239}$ although other authors have found no such association. ${ }^{94,247}$ It seems clear that resuming high-efficacy therapies, mostly natalizumab, in high-risk patients previously treated with these DMTs is associated with a reduced risk of postpartum relapse. ${ }^{88,90,157,200}$

Breastfeeding does not have a harmful effect for women with MS and must not be contraindicated. ${ }^{248,249}$ The protective role of breastfeeding on postpartum activity in MS has long been a matter of controversy. According to some authors, exclusive breastfeeding prevents relapses after childbirth; $;^{94,100,250}$ however, others have found that breastfeeding has no effect on postpartum relapses, and could be a confounding factor considering that women with higher levels of disability and disease activity before and during pregnancy are less likely to choose natural breastfeeding. ${ }^{87,93,98} \mathrm{~A}$ recent meta-analysis showed that breastfeeding, mostly exclusive than not exclusive, appears to be protective against postpartum relapses, with a $43 \%$ lower relapse rate, although it is not possible to exclude the possibility of residual confounding. ${ }^{249}$ Breastfeeding, especially exclusive breastfeeding, determines short- and long-term maternal and newborn health benefits, ${ }^{251-253}$ and women with MS must be encouraged to breastfeed whenever possible. However, until recently, the safety of DMTs during lactation has remained unknown, and breastfeeding was not officially recommended if a patient was on any DMT. Factors related to MS activity and the previous use of DMTs determine the choice of breastfeeding, and so mothers with relapses during pregnancy and more aggressive MS choose to breastfeed less frequently. ${ }^{87,93,97,98,250}$ Resuming DMT seems to be the determinant factor to refuse breastfeeding, ${ }^{62,94,250}$ as the proportion of women with MS who choose to breastfeed is lower among those who have previously received DMT, ${ }^{98,100,247}$ and breastfeeding is the main reason for delaying the resumption of DMT. ${ }^{94}$ Human data on lactation and DMT are scarce, but drugs could theoretically be classified according to their biological plausibility to be transferred into human milk based on their molecular size, protein binding, volume of distribution, lipid solubility, known active transport mechanisms for the drug and possibility of transport from the infant's gut into the bloodstream, known toxic effects in adults, and potential effects on newborn systems. ${ }^{170,254}$

Large molecules such as IFN- $\beta$ and GA are unlikely to be transferred to breast milk and are now considered safe. Only a minimal fraction of the IFN- $\beta$ maternal dose is detected in breast milk, ${ }^{255}$ and the EMA has approved its use during breastfeeding. ${ }^{256}$ Oral DMTs are all small molecules that can be transferred to human milk, and are not therefore recommended during breastfeeding. Cladribine is transferred to breast milk, but its short halflife means that breastfeeding is contraindicated only during treatment and for 1 week after the last dose. ${ }^{164,257}$ Monoclonal antibodies (mAbs) are large molecules that can be detected only at low levels in human milk, and are likely to be partially destroyed in the infant's 
gastrointestinal tract such that absorption by the infant is minimal. ${ }^{258}$ Several reports of nursing mothers on natalizumab have found that there is a correlation between the time since the last natalizumab infusion ${ }^{259}$ and the increase in breast milk concentrations over time with repeat infusions. ${ }^{260,261}$ However, there is thought to be a limited absorption in an infant's gastrointestinal tract, and no longer-term effects on infant immunity and childhood development were observed in a series of 23 infants from mothers treated with natalizumab or anti-CD20 mAbs during lactation, ${ }^{262}$ or in a series of 368 infants followed for $\geq 6$ months after exposure to breast milk of mothers treated with mAbs. ${ }^{260}$ Only a few cases of newborns exposed to ocrelizumab through breast milk have been reported, and transient peripheral B-cell depletion has been observed in one infant (Table 1). ${ }^{263}$

Corticosteroids are only minimally transferred to human milk, levels in milk peak 1 hour after intravenous methylprednisolone administration, and newborn exposure is low. ${ }^{264}$ Thus, the use of intravenous methylprednisolone to treat postpartum relapses is not contraindicated, ${ }^{62,205}$ although some authors recommend delaying breastfeeding for 2-4 hours after administration to minimize infant exposure. $^{265}$ According to these findings, DMT use and breastfeeding are not mutually exclusive and, although not validated, there may be an additive therapeutic effect from DMT to the benefits of breastfeeding ${ }^{248}$ based on an individualized approach. Women without DMT before pregnancy who are stable during pregnancy could be advised to partake in exclusive breastfeeding for at least 6 months and delay the start of DMTs; however, patients who do not wish to breastfeed, and were receiving DMTs prior to pregnancy and stopped them before pregnancy or at conception, should immediately resume their DMTs after delivery.

Women who maintain IFN- $\beta$ or GA throughout pregnancy should be advised to maintain them during breastfeeding. Mothers who have stopped taking IFN- $\beta$ or GA before pregnancy or at conception, especially those at high risk for postpartum relapses, could be advised to both breastfeed and resume DMTs as early as possible, since both are considered safe during lactation. ${ }^{205,255}$ After a benefit-risk discussion, women with a higher risk of postpartum activity (highly active MS pre-pregnancy, a pre-pregnancy Expanded Disability Status Scale score $\geq 2$, previously treated with second-line DMTs, who suffered relapses during pregnancy, or received natalizumab or anti-CD 20 depleting antibodies during pregnancy) could be advised to breastfeed and start or resume natalizumab or anti-CD20 mAbs, in the first 3 days after delivery. ${ }^{61}$ If a woman does not accept the risks, breastfeeding should probably be discouraged and high-efficacy DMTs resumed in the first 3 days after delivery. A case of reversible cerebral vasoconstriction syndrome associated with fingolimod therapy 3 months after childbirth has been reported, which highlights the need to monitor patients who resume DMT soon after delivery if associated symptoms appear. ${ }^{266}$

Patients should be closely monitored during the first year postpartum; MRI is not contraindicated during breastfeeding and, although only a low dose of gadolinium passes to the breast milk and a minimum quantity seems to be absorbed from the infant's gastrointestinal tract, ${ }^{208}$ a breastfeeding pause of 24 hours has been recommended after maternal gadolinium administration, ${ }^{72,170,267}$ but it is probably not necessary. ${ }^{54,127,268}$ After delivery, bowel and urinary disturbances could appear or worsen. An adequate assessment of urinary function, lifestyle recommendations, pelvic floor exercises, and symptomatic medication, if necessary, are recommended.

Newborns exposed to natalizumab during pregnancy, especially in the third trimester, should be monitored after delivery for hematological abnormalities. ${ }^{211-213}$ Predelivery umbilical cord sampling and intravenous immunoglobulin administration could reduce the hematological effects on newborns. ${ }^{212,269}$ The B cell count should be monitored in infants exposed to anti-CD20 mAbs during pregnancy or through breast milk, because B-cell depletion can result in perinatal and neonatal immunosuppression and subsequent infection. ${ }^{127,263,269,270}$ In cases of B-cell depletion, vaccines should not be administered until B-cell reconstitution. ${ }^{109}$ Children of mothers previously treated with alemtuzumab should be monitored for thyroid disorders (Table 1). ${ }^{170}$

\section{Acknowledgment}

This manuscript was edited for English Language by Charlesworth Author Services (www.cwauthors.com).

\section{Author Contributions}

The author made a significant contribution to the work reported, in the conception, study design, execution, acquisition of data, analysis and interpretation; took part in drafting, revising and critically reviewing the article; gave final approval of the version to be published; agreed 
on the journal to which the article has been submitted; and agrees to be accountable for all aspects of the work.

\section{Funding}

No specific funding was received for this work.

\section{Disclosure}

RV has received lecture fees or travel grants from Biogen, Merck, Novartis, Roche, Sanofi, and Teva, personal fees from Sanofi-Genzyme, and reports no other potential conflicts of interest for this work.

\section{References}

1. Coyle PK. Management of women with multiple sclerosis through pregnancy and after childbirth. Ther Adv Neurol Disord. 2016;9(3):198-210. doi:10.1177/1756285616631897

2. Harbo HF, Gold R, Tintore M. Sex and gender issues in multiple sclerosis. Ther Adv Neurol Disord. 2013;6(4):237-248. doi: $10.1177 / 1756285613488434$

3. Thompson AJ, Baranzini SE, Geurts J, Hemmer B, Ciccarelli O. Multiple sclerosis. Lancet. 2018;391(10130):1622-1636. doi:10.1016/S0140-6736(18)30481-1

4. Alonso A, Hernán MA. Temporal trends in the incidence of multiple sclerosis: a systematic review. Neurology. 2008;71 (2):129-135. doi:10.1212/01.wnl.0000316802.35974.34

5. Trojano M, Lucchese G, Graziano G, et al. Geographical variations in sex ratio trends over time in multiple sclerosis. PLoS One. 2012;7(10):e48078. doi:10.1371/journal.pone.0048078

6. Candeliere-Merlicco A, Valero-Delgado F, Martínez-Vidal S, et al. Prevalence of multiple sclerosis in Health District III, Murcia, Spain. Mult Scler Relat Disord. 2016;9:31-35. doi:10.1016/j.msard.2016.06.003

7. Perez-Carmona N, Gimenez-Martinez J, Borrego-Honrubia C, Sempere AP. Multiple sclerosis prevalence and incidence in San Vicente del Raspeig, Spain. Mult Scler Relat Disord. 2019;33:78-81. doi:10.1016/j.msard.2019.05.022

8. Thompson AJ, Banwell BL, Barkhof F, et al. Position paper diagnosis of multiple sclerosis: 2017 revisions of the McDonald criteria. Lancet Neurol. 2018;17(2):162-173. doi:10.1016/S14744422(17)30470-2

9. Rasmussen PV, Magyari M, Moberg JY, Bøgelund M, Jensen UFA, Madsen KG. Patient awareness about family planning represents a major knowledge gap in multiple sclerosis. Mult Scler Relat Disord. 2018;24:129-134. doi:10.1016/j. msard.2018.06.006

10. Runmarker B, Andersen O. Pregnancy is associated with a lower risk of onset and a better prognosis in multiple sclerosis. Brain 1995;118(1):253-261. doi:10.1093/brain/118.1.253

11. Weinshenker BG, Hader W, Carriere W, Baskerville J, Ebers GC. The influence of pregnancy on disability from multiple sclerosis: a population-based study in Middlesex County, Ontario. Neurology. 1989;39(11):1438-1440. doi:10.1212/ WNL.39.11.1438

12. Alwan S, Yee I, Dybalski M, et al. Reproductive decision making after the diagnosis of multiple sclerosis (MS). Mult Scler. 2013;19 (3):351-358. doi:10.1177/1352458512452920

13. Moberg JY, Laursen B, Thygesen LC, Magyari M. Reproductive history of the Danish multiple sclerosis population: a register-based study. Mult Scler. 2020;26(8):902-911. doi: $10.1177 / 1352458519851245$
14. Ferraro D, Simone AM, Adani G, et al. Definitive childlessness in women with multiple sclerosis: a multicenter study. Neurol Sci. 2017;38(8):1453-1459. doi:10.1007/s10072-017-2999-1

15. Houtchens M, Edwards N, Schneider G, Stern K, Phillips AL. Pregnancy rates and outcomes in women with and without MS in the United States. Neurology. 2018;91(17):e1559-e1569. doi:10.1212/WNL.0000000000006384

16. Nguyen AL, Havrdova EK, Horakova D, et al. Incidence of pregnancy and disease-modifying therapy exposure trends in women with multiple sclerosis: a contemporary cohort study. Mult Scler Relat Disord. 2019;28:235-243. doi:10.1016/j. msard.2019.01.003

17. Orton S-M, Herrera BM, Yee IM, et al. Sex ratio of multiple sclerosis in Canada: a longitudinal study. Lancet Neurol. 2006;5 (11):932-936. doi:10.1016/S1474-4422(06)70581-6

18. Gold SM, Willing A, Leypoldt F, Paul F, Friese MA. Sex differences in autoimmune disorders of the central nervous system. Semin Immunopathol. 2019;41(2):177-188. doi:10.1007/s00281018-0723-8

19. Sellner J, Kraus J, Awad A, Milo R, Hemmer B, Stüve O. The increasing incidence and prevalence of female multiple sclerosisa critical analysis of potential environmental factors. Autoimmun Rev. 2011;10(8):495-502. doi:10.1016/j.autrev.2011.02.006

20. Kalincik T, Vivek V, Jokubaitis V, et al. Sex as a determinant of relapse incidence and progressive course of multiple sclerosis. Brain. 2013;136(12):3609-3617. doi:10.1093/brain/awt281

21. Pozzilli C, Tomassini V, Marinelli F, Paolillo A, Gasperini C, Bastianello S. "Gender gap" in multiple sclerosis: magnetic resonance imaging evidence. Eur $J$ Neurol. 2003;10(1):95-97. doi:10.1046/j.1468-1331.2003.00519.x

22. Weinshenker BG, Rice GP, Noseworthy JH, Carriere W, Baskerville J, Ebers GC. The natural history of multiple sclerosis: a geographically based study. 3. Multivariate analysis of predictive factors and models of outcome. Brain. 1991;114 (Pt2):1045-1056. doi:10.1093/brain/114.2.1045

23. Confavreux C, Vukusic S, Adeleine P. Early clinical predictors and progression of irreversible disability in multiple sclerosis: an amnesic process. Brain. 2003;126(4):770-782. doi:10.1093/brain/ awg081

24. Tremlett H, Zhao Y, Rieckmann P, Hutchinson M. New perspectives in the natural history of multiple sclerosis. Neurology. 2010;74(24):2004-2015. doi:10.1212/WNL.0b013e3181e3973f

25. Schoonheim MM, Popescu V, Rueda Lopes FC, et al. Subcortical atrophy and cognition: sex effects in multiple sclerosis. Neurology. 2012;79(17):1754-1761. doi:10.1212/ WNL.0b013e3182703f46

26. Koch M, Kingwell E, Rieckmann P, et al. The natural history of secondary progressive multiple sclerosis. J Neurol Neurosurg Psychiatry. 2010;81(9):1039-1043. doi:10.1136/jnnp.2010.208173

27. Voskuhl RR, Gold SM. Sex-related factors in multiple sclerosis susceptibility and progression. Nat Rev Neurol. 2012;8 (5):255-263. doi:10.1038/nrneurol.2012.43

28. Airas L. Hormonal and gender-related immune changes in multiple sclerosis. Acta Neurol Scand. 2015;132(199):62-70. doi:10.1111/ane.12433

29. Bove RM, Healy B, Augustine A, Musallam A, Gholipour T, Chitnis T. Effect of gender on late-onset multiple sclerosis. Mult Scler. 2012;18(10):1472-1479. doi:10.1177/1352458512438236

30. Alonso A, Jick SS, Olek MJ, Ascherio A, Jick H, Hernan MA. Recent use of oral contraceptives and the risk of multiple sclerosis. Arch Neurol. 2005;62(9):1362-1365. doi:10.1001/ archneur.62.9.1362

31. Nelson LM, Franklin GM, Jones MC. Risk of multiple sclerosis exacerbation during pregnancy and breast-feeding. JAMA. 1988;259(23):3441-3443. doi:10.1001/jama.1988.0372023 0051029 
32. Bernardi S, Grasso M, Bertollini R, Orzi F, Fieschi C. The influence of pregnancy on relapses in multiple sclerosis: a cohort study. Acta Neurol Scand. 1991;84(5):403-406. doi:10.1111/j.1600-0404.1991.tb04977.x

33. Villard-Mackintosh L, Vessey MP. Oral contraceptives and reproductive factors in multiple sclerosis incidence. Contraception. 1993;47(2):161-168. doi:10.1016/0010-7824(93)90088-O

34. Hernán MA, Hohol MJ, Olek MJ, Spiegelman D, Ascherio A. Oral contraceptives and the incidence of multiple sclerosis. Neurology. 2000;55(6):848-854. doi:10.1212/WNL.55.6.848

35. Thorogood M, Hannaford PC. The influence of oral contraceptives on the risk of multiple sclerosis. Br J Obstet Gynaecol. 1998;105(12):1296-1299. doi:10.1111/j.1471-0528.1998. tb10008.x

36. Langer-Gould A, Smith JB, Hellwig K, et al. Breastfeeding, ovulatory years, and risk of multiple sclerosis. Neurology. 2017;89(6):563-569. doi:10.1212/WNL.0000000000004207

37. Magyari M. Role of socio-economic and reproductive factors in the risk of multiple sclerosis. Acta Neurol Scand. 2015;132 (199):20-23. doi:10.1111/ane.12426

38. Ponsonby A, Lucas R, van der Mei I, et al. Offspring number, pregnancy, and risk of a first clinical demyelinating event: the AusImmune Study. Neurology. 2012;78(12):867-874. doi:10.1212/WNL.0b013e31824c4648

39. Nguyen AL, Vodehnalova K, Kalincik T, et al. Association of pregnancy with the onset of clinically isolated syndrome. JAMA Neurol. 2020;77(12):1496-1503. doi:10.1001/jamaneurol. 2020.3324

40. Krysko K, Graves JS, Dobson R, et al. Sex effects across the lifespan in women with multiple sclerosis. Ther Adv Neurol Disord. 2020;13:1756286420936166. doi:10.1177/17562864 20936166

41. Wijnands JMA, Kingwell E, Zhu F, et al. Health-care use before a first demyelinating event suggestive of a multiple sclerosis prodrome: a matched cohort study. Lancet Neurol. 2017;16 (6):445-451. doi:10.1016/S1474-4422(17)30076-5

42. Lebrun C, Cohen M, Chaussenot A, Mondot L, Chanalet S. A prospective study of patients with brain MRI showing incidental t2 hyperintensities addressed as multiple sclerosis: a lot of work to do before treating. Neurol Ther. 2014;3(2):123-132. doi:10.1007/s40120-014-0024-7

43. Grinsted L, Heltberg A, Hagen C, Djursing H. Serum sex hormone and gonadotropin concentrations in premenopausal women with multiple sclerosis. J Int Med. 1989;226(4):241-244. doi:10.1111/j.1365-2796.1989.tb01387.x

44. Thone J, Kollar S, Nousome D, et al. Serum anti-Mullerian hormone levels in reproductive-age women with relapsing-remitting multiple sclerosis. Mult Scler. 2014;21 (1):41-47. doi:10.1177/1352458514540843

45. Sepúlveda M, Ros C, Martínez-Lapiscina EH, et al. Pituitaryovary axis and ovarian reserve in fertile women with multiple sclerosis: a pilot study. Mult Scler. 2016;22(4):564-568. doi:10.1177/1352458515602339

46. Amato MP, Portaccio E. Fertility, pregnancy and childbirth in patients with multiple sclerosis: impact of disease-modifying drugs. CNS Drugs. 2015;29(3):207-220. doi:10.1007/s40263015-0238-y

47. Hellwig K. Pregnancy in multiple sclerosis. Eur Neurol. 2014;72 (Suppl 1):39-42. doi:10.1159/000367640

48. Hellwig K, Correale J. Artificial reproductive techniques in multiple sclerosis. Clin Immunol. 2013;149(2):219-224. doi:10.1016/j. clim.2013.02.001

49. Roux T, Courtillot C, Debs R, Touraine P, Lubetzki C, Papeix C. Fecundity in women with multiple sclerosis: an observational mono-centric study. $J$ Neurol. 2015;262(4):957-960. doi:10.1007/s00415-015-7663-1
50. Soler B, Ciampi E, Uribe-San-Martín R, et al. Pregnancy outcomes in women with multiple sclerosis. Mult Scler Relat Disord. 2021;48:102682. doi:10.1016/j.msard.2020.102682

51. Chen YH, Lin HL, Lin HC. Does multiple sclerosis increase risk of adverse pregnancy outcomes? A population-based study. Mult Scler. 2009;15(5):606-612. doi:10.1177/1352458508101937

52. Bodiguel E, Bensa C, Brassat D, et al. Multiple sclerosis and pregnancy. Rev Neurol (Paris). 2014;170(4):247-265. doi:10.1016/j.neurol.2013.09.010

53. MacDonald SC, McElrath TF, Hernández-Díaz S. Pregnancy outcomes in women with multiple sclerosis. Am J Epidemiol. 2019;188(1):57-66. doi:10.1093/aje/kwy197

54. Bove R, Alwan S, Friedman JM, et al. Management of multiple sclerosis during pregnancy and the reproductive years. Obstet Gynecol. 2014;124(6):1157-1168. doi:10.1097/AOG.00000 00000000541

55. van der Kop ML, Pearce MS, Dahlgren L, et al. Neonatal and delivery outcomes in women with multiple sclerosis. Ann Neurol. 2011;70(1):41-50. doi:10.1002/ana.22483

56. Jalkanen A, Alanen A, Airas L; Finnish Multiple Sclerosis and Pregnancy Study Group. Pregnancy outcome in women with multiple sclerosis: results from a prospective nationwide study in Finland. Mult Scler. 2010;16(8):950-955. doi:10.1177/ 1352458510372629

57. Amato MP, Bertolotto A, Brunelli R, et al. Management of pregnancy-related issues in multiple sclerosis patients: the need for an interdisciplinary approach. Neurol Sci. 2017;38 (10):1849-1858. doi:10.1007/s10072-017-3081-8

58. MacDonald SC, McElrath TF, Hernández-Díaz S. Use and safety of disease-modifying therapy in pregnant women with multiple sclerosis. Pharmacoepidemiol Drug Saf. 2019;28(4):556-560. doi:10.1002/pds.4735

59. Confavreux C, Hutchinson M, Hours MM, Cortinovis-Tourniaire P, Moreau T. Rate of pregnancy-related relapse in multiple sclerosis. Pregnancy in Multiple Sclerosis Group. $N$ Engl J Med. 1998;339(5):285-291. doi:10.1056/NEJM199807303390501

60. Vukusic S, Confavreux C. Pregnancy and multiple sclerosis: the children of PRIMS. Clin Neurol Neurosurg. 2006;108 (3):266-270. doi:10.1016/j.clineuro.2005.11.016

61. Vukusic S, Marignier R. Multiple sclerosis and pregnancy in the "treatment era.". Nat Rev Neurol. 2015;11(5):280-289. doi:10.1038/nrneurol.2015.53

62. Fernandez Liguori N, Klajn D, Acion L, et al. Epidemiological characteristics of pregnancy, delivery, and birth outcome in women with multiple sclerosis in Argentina (EMEMAR study). Mult Scler. 2009;15(5):555-562. doi:10.1177/1352458509102366

63. Finkelsztejn A, Fragoso Y, Ferreira ML, et al. The Brazilian database on pregnancy in multiple sclerosis. Clin Neurol Neurosurg. 2011;113:277-280. doi:10.1016/j. clineuro.2010.11.016

64. Hellwig K, Haghikia A, Rockhoff M, Gold R. Multiple sclerosis and pregnancy: experience from a nationwide database in Germany. Ther Adv Neurol Disord. 2012;5(5):247-253. doi:10.1177/1756285612453192

65. Jesus-Ribeiro J, Correia I, Martins AI, et al. Pregnancy in multiple sclerosis: a Portuguese cohort study. Mult Scler Relat Disord. 2017;17:63-68. doi:10.1016/j.msard.2017.07.002

66. Dobson R, Jokubaitis VG, Giovannoni G. Change in pregnancy-associated multiple sclerosis relapse rates over time: a meta-analysis. Mult Scler Relat Disord. 2020;44:102241. doi:10.1016/j.msard.2020.102241

67. Finkelsztejn A, Brooks JBB, Paschoal FM, Fragoso YD. What can we really tell women with multiple sclerosis regarding pregnancy? A systematic review and meta-analysis of the literature. BJOG. 2011;118(7):790-797. doi:10.1111/j.1471-0528.20 11.02931.x 
68. Modrego PJ, Urrea MA, de Cerio LD. The effects of pregnancy on relapse rates, disability and peripartum outcomes in women with multiple sclerosis: a systematic review and meta-analysis. J Comp Eff Res. 2021;10(3):175-186. doi:10.2217/cer-2020-0211

69. Paavilainen T, Kurki T, Parkkola R, et al. Magnetic resonance imaging of the brain used to detect early post-partum activation of multiple sclerosis. Eur J Neurol. 2007;14(11):1216-1221. doi:10.1111/j.1468-1331.2007.01927.x

70. van Walderveen MA, Tas MW, Barkhof F, et al. Magnetic resonance evaluation of disease activity during pregnancy in multiple sclerosis. Neurology. 1994;44(2):327-329. doi:10.1212/ WNL.44.2.327

71. Saraste MH, Kurki T, Airas LM. Postpartum activation of multiple sclerosis: MRI imaging and immunological characterization of a case. Eur J Neurol. 2006;13(1):98-99. doi:10.1111/j.14681331.2006.01108.x

72. Fabian M. Pregnancy in the setting of multiple sclerosis. Continuum (Minneap Minn). 2016;22(3):837-850. doi:10.1212/ CON.0000000000000328

73. Patas K, Engler JB, Friese MA, Gold SM. Pregnancy and multiple sclerosis: feto-maternal immune cross talk and its implications for disease activity. J Reprod Immunol. 2013;97(1):140-146. doi:10.1016/j.jri.2012.10.005

74. Bouman A, Heineman MJ, Faas MM. Sex hormones and the immune response in humans. Hum Reprod Update. 2005;11 (4):411-423. doi:10.1093/humupd/dmi008

75. Phiel KL, Henderson RA, Adelman SJ, Elloso MM. Differential estrogen receptor gene expression in human peripheral blood mononuclear cell populations. Immunol Lett. 2005;97 (1):107-113. doi:10.1016/j.imlet.2004.10.007

76. Robinson DP, Klein SL. Pregnancy and pregnancy-associated hormones alter immune responses and disease pathogenesis. Horm Behav. 2012;62(3):263-271. doi:10.1016/j.yhbeh.2012.02.023

77. Airas L, Saraste M, Rinta S, et al. Immunoregulatory factors in multiple sclerosis patients during and after pregnancy: relevance of natural killer cells. Clin Exp Immunol. 2008;151(2):235-243. doi:10.1111/j.1365-2249.2007.03555.x

78. de Andrés C, Fernández-Paredes L, Tejera-Alhambra M, Alonso B, Ramos-Medina R, Sánchez-Ramón S. Activation of blood CD3+CD56+CD8+ T cells during pregnancy and multiple sclerosis. Front Immunol. 2017;8:196. doi:10.3389/ fimmu.2017.00196

79. Neuteboom RF, Verbraak E, Wierenga-Wolf AF, et al. The monocyte transcriptome during pregnancy in multiple sclerosis: prominent expression of the Fc-receptor CD64. Mult Scler. 2011;17 (4):389-396. doi:10.1177/1352458510389628

80. Sánchez-Ramón S, Navarro AJ, Aristimuño C, et al. Pregnancyinduced expansion of regulatory T-lymphocytes may mediate protection to multiple sclerosis activity. Immunol Lett. 2005;96 (2):195-201. doi:10.1016/j.imlet.2004.09.004

81. Schumacher M, Mattern C, Ghoumari A, et al. Revisiting the roles of progesterone and allopregnanolone in the nervous system: resurgence of the progesterone receptors. Prog Neurobiol. 2014;113:6-39. doi:10.1016/j.pneurobio.2013.09.004

82. El-Etr M, Rame M, Boucher C, et al. Progesterone and nestorone promote myelin regeneration in chronic demyelinating lesions of corpus callosum and cerebral cortex. Glia. 2015;63(1):104-117. doi:10.1002/glia.22736

83. Benoit A, Durand-Dubief F, Amato MP, et al. History of multiple sclerosis in 2 successive pregnancies. A French and Italian cohort. Neurology. 2016;87:1360-1367. doi:10.1212/WNL.0000 000000003036

84. Hellwig K, Brune N, Haghikia A, et al. Reproductive counselling, treatment and course of pregnancy in 73 German MS patients. Acta Neurol Scand. 2008;118(1):24-28. doi:10.1111/j.16000404.2007.00978.x
85. Herbstritt S, Langer-Gould A, Rockhoff M, et al. Glatiramer acetate during early pregnancy: a prospective cohort study. Mult Scler. 2016;22(6):810-816. doi:10.1177/1352458515623366

86. Saraste M, Väisänen S, Alanen A, Airas L; Finnish Multiple Sclerosis and Pregnancy Study Group. Clinical and immunologic evaluation of women with multiple sclerosis during and after pregnancy. Gend Med. 2007;4(1):45-55. doi:10.1016/S15508579(07)80008-8

87. Vukusic S, Hutchinson M, Hours M, et al. Pregnancy and multiple sclerosis (the PRIMS study): clinical predictors of post-partum relapse. Brain. 2004;127(6):1353-1360. doi:10.1093/brain/awh152

88. Bsteh G, Algrang L, Hegen H, et al. Pregnancy and multiple sclerosis in the DMT era: a cohort study in Western Austria. Mult Scler. 2020;26(1):69-78. doi:10.1177/1352458518816614

89. Thiel S, Langer-Gould A, Rockhoff $\mathrm{M}$, et al. Interferon-beta exposure during first trimester is safe in women with multiple sclerosis-A prospective cohort study from the German Multiple Sclerosis and Pregnancy Registry. Mult Scler. 2016;22 (6):801-809. doi:10.1177/1352458516634872

90. Yeh WZ, Widyastuti PA, van der Walt A, et al. Natalizumab, fingolimod and dimethyl fumarate use and pregnancy-related relapse and disability in women with multiple sclerosis. Neurology. 2021;96(24):e2989-e3002. doi:10.1212/WNL.0000 000000012084

91. Alroughani R, Akhtar S, Zeineddine M, et al. Risk of relapses during pregnancy among multiple sclerosis patients. Mult Scler Relat Disord. 2019;34:9-13. doi:10.1016/j.msard.2019.06.007

92. Villaverde-González R, Candeliere-Merlicco A, Alonso-Frías $\mathrm{MA}$, et al. Discontinuation of disease-modifying treatments in multiple sclerosis to plan a pregnancy: a retrospective registry study. Mult Scler Relat Disord. 2020;46:102518. doi:10.1016/j. msard.2020.102518

93. Airas L, Jalkanen A, Alanen A, Pirttilä T, Marttila RJ. Breastfeeding, postpartum and prepregnancy disease activity in multiple sclerosis. Neurology. 2010;75(5):474-476. doi:10.1212/ WNL.0b013e3181eb5860

94. Langer-Gould A, Smith JB, Albers KB, et al. Pregnancy-related relapses and breastfeeding in a contemporary multiple sclerosis cohort. Neurology. 2020;94(18):e1939-e1949. doi:10.1212/ WNL.0000000000009374

95. Roullet E, Verdier-Taillefer MH, Amarenco P, Gharbi G, Alperovitch A, Marteau R. Pregnancy and multiple sclerosis: a longitudinal study of 125 remittent patients. J Neurol Neurosurg Psychiatry. 1993;56(10):1062-1065. doi:10.1136/jnnp.56.10.1062

96. Worthington J, Jones R, Crawford M, Forti A. Pregnancy and multiple sclerosis-a 3-year prospective study. J Neurol. 1994;241 (4):228-233. doi:10.1007/BF00863773

97. Pastò L, Portaccio E, Ghezzi A, et al. Epidural analgesia and cesarean delivery in multiple sclerosis post-partum relapses: the Italian cohort study. BMC Neurol. 2012;12:165. doi:10.1186/ 1471-2377-12-165

98. Portaccio E, Ghezzi A, Hakiki B, et al. Breastfeeding is not related to postpartum relapses in multiple sclerosis. Neurology. 2011;77(2):145-150. doi:10.1212/WNL.0b013e318224afc9

99. Hughes SE, Spelman T, Gray OM, et al. Predictors and dynamics of postpartum relapses in women with multiple sclerosis. Mult Scler. 2014;20(6):739-746. doi:10.1177/1352458513507816

100. Hellwig K, Rockhoff M, Herbstritt S, et al. Exclusive breastfeeding and the effect on postpartum multiple sclerosis relapses. JAMA Neurol. 2015;72(10):1132-1138. doi:10.1001/jamane urol.2015.1806

101. Koch M, Uyttenboogaart M, Heersema D, Steen C, de Keyser J. Parity and secondary progression in multiple sclerosis. J Neurol Neurosurg Psychiatry. 2009;80(6):676-678. doi:10.1136/ jnnp.2008.160911 
102. Karp I, Manganas A, Sylvestre MP, Ho A, Roger E, Duquette P. Does pregnancy alter the long-term course of multiple sclerosis? Ann Epidemiol. 2014;24(7):504-508.e2. doi:10.1016/j. annepidem.2014.04.007

103. D'Hooghe MB, Nagels G, Uitdehaag BMJ. Long-term effects of childbirth in MS. J Neurol Neurosurg Psychiatry. 2010;81 (1):38-41. doi:10.1136/jnnp.2008.163816

104. Masera S, Cavalla P, Prosperini L, et al. Parity is associated with a longer time to reach irreversible disability milestones in women with multiple sclerosis. Mult Scler. 2015;21(10):1291-1297. doi: $10.1177 / 1352458514561907$

105. Zeydan B, Atkinson EJ, Weis DM, et al. Reproductive history and progressive multiple sclerosis risk in women. Brain Commun. 2020;2(2):fcaa185. doi:10.1093/braincomms/fcaa185

106. Munger KL, Åivo J, Hongell K, et al. Vitamin D status during pregnancy and risk of multiple sclerosis in offspring of women in the Finnish Maternity Cohort. JAMA Neurol. 2016;73 (5):515-519. doi:10.1001/jamaneurol.2015.4800

107. Mirzaei F, Michels KB, Munger K, et al. Gestational vitamin $\mathrm{D}$ and the risk of multiple sclerosis in offspring. Ann Neurol. 2011;70(1):30-40. doi:10.1002/ana.22456

108. Drug and Therapeutic Bulletin. Vitamin supplementation in pregnancy. Drug Ther Bull. 2016;54(7):81-84. doi:10.1136/ dtb.2016.7.0414

109. Coyle PK, Oh J, Magyari M, Oreja-Guevara C, Houtchens M. Management strategies for female patients of reproductive potential with multiple sclerosis: an evidence-based review. Mult Scler Relat Disord. 2019;32:54-63. doi:10.1016/j.msard.2019.04.003

110. Seier M, Hiller A. Parkinson's disease and pregnancy: an updated review. Parkinsonism Relat Disord. 2017;40:11-17. doi:10.1016/ j.parkreldis.2017.05.007

111. Baclofen and pregnancy: birth defects and withdrawal symptoms. Prescrire Int. 2015;24(163):214.

112. Tandon SS, Hoskins I, Azhar S. Intrathecal baclofen pump a viable therapeutic option in pregnancy. Obstet Med. 2010;3 (3):119-120. doi:10.1258/om.2010.100016

113. Maillart E, Gout O, Lubetzki C, Carpentier B, Nizard J. Favorable outcome of a pregnancy after fampridine exposition during the first month. J Neurol Sci. 2016;370:158. doi:10.1016/j. jns.2016.09.033

114. Cuello JP, Martínez Ginés ML, Martin Barriga ML, de Andrés C. Multiple sclerosis and pregnancy: a single-centre prospective comparative study. Neurologia. 2017;32(2):92-98. doi:10.1016/j. nrl.2014.12.015

115. Mahlanza TD, Manieri MC, Klawiter EC, et al. Prospective growth and developmental outcomes in infants born to mothers with multiple sclerosis. Mult Scler. 2021;27(1):79-89. doi:10.1177/1352458520904545

116. Laplaud D-A, Leray E, Barriere P, Wiertlewski S, Moreau T. Increase in multiple sclerosis relapse rate following in vitro fertilization. Neurology. 2006;66(8):1280-1281. doi:10.1212/01. wnl.0000208521.10685.a6

117. Hellwig K, Beste C, Brune N, et al. Increased MS relapse rate during assisted reproduction technique. J Neurol. 2008;255 (4):592-593. doi:10.1007/s00415-008-0607-2

118. Michel L, Foucher Y, Vukusic S, et al. Increased risk of multiple sclerosis relapse after in vitro fertilisation. $J$ Neurol Neurosurg Psychiatry. 2012;83(8):796-802. doi:10.1136/jnnp-2012-302235

119. Correale J, Farez MF, Ysrraelit MC. Increase in multiple sclerosis activity after assisted reproduction technology. Ann Neurol. 2012;72(5):682-694. doi:10.1002/ana.23745

120. Bove R, Rankin K, Lin C, et al. Effect of assisted reproductive technology on multiple sclerosis relapses: case series and meta-analysis. Mult Scler. 2020;26(11):1410-1419. doi:10.1177/ 1352458519865118
121. Brzosko B, Thiel S, Gold R, Hellwig K. Low relapse risk under disease modifying treatment during ART in women with relapsing remitting multiple sclerosis. Neurology. 2018;90(15 Supplement): P4.356.

122. Rae-Grant A, Day GS, Marrie RA, et al. Practice guideline recommendations summary: disease-modifying therapies for adults with multiple sclerosis. Neurology. 2018;90(17):777-788. doi:10.1212/WNL.0000000000005347

123. Giovannoni G, Butzkueven H, Dhib-Jalbut S, et al. Brain health: time matters in multiple sclerosis. Mult Scler Relat Disord. 2016;9:S5-S48. doi:10.1016/j.msard.2016.07.003

124. Dargahi N, Katsara M, Tselios T, et al. Multiple sclerosis: immunopathology and treatment update. Brain Sci. 2017;7(7):78. doi:10.3390/brainsci7070078

125. Fragoso Y, Boggild M, Macias-Islas MA, et al. The effects of long-term exposure to disease-modifying drugs during pregnancy in multiple sclerosis. Clin Neurol Neurosurg. 2013;115:154-159. doi:10.1016/j.clineuro.2012.04.024

126. Alroughani R, Inshasi J, Al-Asmi A, et al. Disease-modifying drugs and family planning in people with multiple sclerosis: a consensus narrative review from the Gulf Region. Neurol Ther. 2020;9(2):265-280. doi:10.1007/s40120-020-00201-8

127. Canibaño B, Deleu D, Mesraoua B, Melikyan G, Ibrahim F, Hanssens Y. Pregnancy-related issues in women with multiple sclerosis: an evidence-based review with practical recommendations. J Drug Asses. 2020;9(1):20-36. doi:10.1080/ 21556660.2020.1721507

128. Houtchens MK, Zapata LB, Curtis KM, Whiteman MK. Contraception for women with multiple sclerosis: guidance for healthcare providers. Mult Scler. 2017;23(6):757-764. doi: $10.1177 / 1352458517701314$

129. Singh S, Sedgh G, Hussain R. Unintended pregnancy: worldwide levels, trends and outcomes. Stud Fam Plann. 2010;41 (4):241-250. doi:10.1111/j.1728-4465.2010.00250.x

130. Rasch V. Contraceptive failure-results from a study conducted among women with accepted and unaccepted pregnancies in Denmark. Contraception. 2002;66(2):109-116. doi:10.1016/ S0010-7824(02)00325-6

131. Hakkarainen K, Juuti R, Burkill S, et al. Pregnancy outcomes after exposure to interferon beta: a register-based cohort study among women with MS in Finland and Sweden. Ther Adv Neurol Disord. 2020;13:1756286420951072.

132. Hellwig K, Geissbuehler Y, Sabidó M, et al. Pregnancy outcomes in interferon-beta-exposed patients with multiple sclerosis: results from the European Interferon-beta Pregnancy Registry. $J$ Neurol. 2020;267(6):1715-1723. doi:10.1007/s00415-020-09762-y

133. Sandberg-Wollheim M, Alteri E, Moraga M, Kornmann G. Pregnancy outcomes in multiple sclerosis following subcutaneous interferon beta-1a therapy. Mult Scler. 2011;17(4):423-430. doi: $10.1177 / 1352458510394610$

134. Tomczyk S, Sperling B. Post-marketing pregnancy outcomes in patients exposed to intramuscular interferon- $\beta-1 \mathrm{a}$. Neurology. 2013;80(Meeting Abstracts 1):S30.006.

135. Coyle PK, Sinclair SM, Scheuerle AE, Thorp JM, Albano JD, Rametta MJ. Final results from the Betaseron (interferon $\beta-1 b$ ) pregnancy registry: a prospective observational study of birth defects and pregnancy-related adverse events. BMJ Open. 2014;4(5):e004536. doi:10.1136/bmjopen-2013-004536

136. Amato MP, Portaccio E, Ghezzi A, et al. Pregnancy and fetal outcomes after interferon- $\beta$ exposure in multiple sclerosis. Neurology. 2010;75(20):1794-1802. doi:10.1212/ WNL.0b013e3181fd62bb

137. Boskovic R, Wide R, Wolpin J, Bauer DJ, Koren G. The reproductive effects of beta interferon therapy in pregnancy: a longitudinal cohort. Neurology. 2005;65(6):807-811. doi:10.1212/01.wnl.0000180575.77021.c4 
138. Lu E, Wang BW, Guimond C, Synnes A, Sadovnick D, Tremlett H. Disease-modifying drugs for multiple sclerosis in pregnancy; A systematic review. Neurology. 2012;79 (11):1130-1135. doi:10.1212/WNL.0b013e3182698c64

139. Weber-Schoendorfer C, Schaefer C. Multiple sclerosis, immunomodulators, and pregnancy outcome: a prospective observational study. Mult Scler. 2009;15(9):1037-1042. doi:10.1177/ 1352458509106543

140. Patti F, Cavallaro T, Lo Fermo S, et al. Is in utero early-exposure to interferon beta a risk factor for pregnancy outcomes in multiple sclerosis? $J$ Neurol. 2008;255(8):1250-1253. doi:10.1007/ s00415-008-0909-4

141. Romero RS, Lünzmann C, Bugge J-P. Pregnancy outcomes in patients exposed to interferon beta-1b. J Neurol Neurosurg Psychiatry. 2015;86(5):587-589. doi:10.1136/jnnp-2014-308113

142. Giannini M, Portaccio E, Ghezzi A, et al. Pregnancy and fetal outcomes after Glatiramer Acetate exposure in patients with multiple sclerosis: a prospective observational multicentric study. BMC Neurol. 2012;12:124. doi:10.1001/jamaneurol.2019.4173

143. Sandberg-Wollheim M, Neudorfer O, Grinspan A, et al. Pregnancy outcomes from the Branded glatiramer acetate pregnancy database. Int J MS Care. 2018;20(1):9-14. doi:10.7224/ 1537-2073.2016-079

144. Fragoso YD, Finkelsztejn A, Comini-Frota ER, et al. Pregnancy and multiple sclerosis: the initial results from a Brazilian database. Arq Neuropsiquiatr. 2009;67(3A):657-660. doi:10.1590/S0004-282X2009000400015

145. Fragoso YD, Finkelsztejn A, Kaimen-Maciel DR, et al. Longterm use of glatiramer acetate by 11 pregnant women with multiple sclerosis. CNS Drugs. 2010;24(11):969-976. doi:10.2165/ 11538960-000000000-00000

146. Salminen HJ, Leggett H, Boggild M. Glatiramer acetate exposure in pregnancy: preliminary safety and birth outcomes. $J$ Neurol. 2010;257(12):2020-2023. doi:10.1007/s00415-010-5652-y

147. Dung AAD, Panda AK. Interferon beta-1a therapy for multiple sclerosis during pregnancy: an unresolved issue. BMJ Case Rep. 2014;2014:bcr2013201273. doi:10.1136/bcr-2013-201273

148. Hellwig K, Gold R. Glatiramer acetate and interferon-beta throughout gestation and postpartum in women with multiple sclerosis J Neurol. 2011;258(3):502-503. doi:10.1007/s00415-010-5758-2

149. Gold R, Giovannoni G, Phillips JT, et al. Efficacy and safety of delayed-release dimethyl fumarate in patients newly diagnosed with relapsing-remitting multiple sclerosis (RRMS). Mult Scler. 2015;21(1):57-66. doi:10.1177/1352458514537013

150. Hellwig K, Rog D, McGuigan C, Chen K, Parks B, Jones C An international registry tracking pregnancy outcomes in women treated with dimethyl fumarate. Abstract (P1147) at the ECTRIMS 2019 congress; September 11-13, 2019; Stockholm, Sweden. Available from: https://onlinelibrary.ectrims-congress. eu/. Accessed December 22, 2021.

151. Vaughn C, Bushra A, Kolb C, Weinstock-Guttman B. An update on the use of disease-modifying therapy in pregnant patients with multiple sclerosis. CNS Drugs. 2018;32(2):161-178. doi:10.1007 s40263-018-0496-6

152. The European Medicines Agency - EMA. Tecfidera. Summary of product characteristics. (Online). Available from: https://www. ema.europa.eu/en/documents/product-information/tecfidera-eparproduct-information_en.pdf. Accessed August 2, 2021.

153. The European Medicines Agency - EMA. Mayzent. Summary of product characteristics. (Online). Available from: https://www. ema.europa.eu/en/documents/product-information/mayzent-eparproduct-information_en.pdf. Accessed August 2, 2021.

154. The European Medicines Agency - EMA. Gilenya. Summary of product characteristics. (Online). Available from: https://www. ema.europa.eu/en/documents/product-information/gilenya-eparproduct-information es.pdf. Accessed August 2, 2021.
155. Koren G, Ornoy A. The role of the placenta in drug transport and fetal drug exposure. Expert Rev Clin Pharmacol. 2018;11 (4):373-385. doi:10.1080/17512433.2018.1425615

156. Demortiere S, Rico A, Maarouf A, Boutiere C, Pelletier J, Audoin B. Maintenance of natalizumab during the first trimester of pregnancy in active multiple sclerosis. Mult Scler. 2021;27 (5):712-718. doi:10.1177/1352458520912637

157. Portaccio E, Moiola L, Martinelli V, et al. Pregnancy decision-making in women with multiple sclerosis treated with natalizumab II: maternal risks. Neurology. 2018;90(10):e832e839. doi:10.1212/WNL.0000000000005068

158. Portaccio E, Annovazzi P, Ghezzi A, et al. Pregnancy decision-making in women with multiple sclerosis treated with natalizumab I: fetal risks. Neurology. 2018;90(10):e823-831. doi:10.1212/WNL.0000000000005067

159. Hellwig K, Haghikia A, Gold R. Pregnancy and natalizumab: results of an observational study in 35 accidental pregnancies during natalizumab treatment. Mult Scler. 2011;17(8):958-963. doi: $10.1177 / 1352458511401944$

160. Ebrahimi N, Herbstritt S, Gold R, Amezcua L, Koren G, Hellwig K. Pregnancy and fetal outcomes following natalizumab exposure in pregnancy. A prospective, controlled observational study. Mult Scler. 2015;21(2):198-205. doi:10.1177/ 1352458514546790

161. Friend S, Richman S, Bloomgren G, Cristiano LM, Wenten M. Evaluation of pregnancy outcomes from the Tysabri ${ }^{\circledR}$ (natalizumab) pregnancy exposure registry: a global, observational, follow-up study. BMC Neurol. 2016;16(1):150. doi:10.1186/s12883016-0674-4

162. Montalban X, Gold R, Thompson AJ, et al. ECTRIMS/EAN guideline on the pharmacological treatment of people with multiple sclerosis. Mult Scler. 2018;24(2):96-120. doi:10.1177/ 1352458517751049

163. Houtchens MK, Kaplan TB. Reproductive issues in MS. Semin Neurol. 2017;37(6):632-642. doi:10.1055/s-0037-1608925

164. The European Medicines Agency - EMA. Mavenclad. Summary of product characteristics. (Online). Available from: https://ec.europa. eu/health/documents/community-register/2017/20170822138481/ anx_138481_es.pdf. Accessed August 2, 2021.

165. The European Medicines Agency - EMA. Lemtrada. Summary of product characteristics. (Online). Available from: https://www. ema.europa.eu/en/documents/product-information/lemtrada-eparproduct-information_en.pdf. Accessed August 2, 2021.

166. Klink DT, van Elburg RM, Schreurs MWJ, van Well GTJ. Rituximab administration in third trimester of pregnancy suppresses neonatal B-cell development. Clin Dev Immunol. 2008;2008:271363. doi: $10.1155 / 2008 / 271363$

167. U.S. Food and Drug Administration - FDA. Ocrevus (ocrelizumab). Prescribing information. Available from: https://www. accessdata.fda.gov/drugsatfda_docs/labe1/2017/761053lbl.pdf. Accessed August 2, 2021.

168. The European Medicines Agency - EMA. Ocrevus. Summary of product characteristics. Available from: https://www.ema.europa. eu/en/documents/product-information/ocrevus-epar-productinformation en.pdf. Accessed August 2, 2021.

169. Stahnke $\mathrm{AM}$, Holt KM. Ocrelizumab: a new B-cell therapy for relapsing remitting and primary progressive multiple sclerosis. Ann Pharmacother. 2018;52(5):473-483. doi:10.1177/ 1060028017747635

170. Langer-Gould AM. Pregnancy and family planning in multiple sclerosis. Continuum (Minneap Minn). 2019;25(3):773-792. doi: $10.1212 / C O N .0000000000000745$

171. Alroughani R, Alowayesh MS, Ahmed SF, Behbehani R, AlHashel J. Relapse occurrence in women with multiple sclerosis during pregnancy in the new treatment era. Neurology. 2018;90 (10):e840-e846. doi:10.1212/WNL.0000000000005065 
172. Oreja-Guevara C, Kobelt G, Berg J, Capsa D, Eriksson J. European multiple sclerosis platform. New insights into the burden and costs of multiple sclerosis in Europe: results for Spain. Mult Scler. 2017;23(Suppl 2):166-178. doi:10.1177/ 1352458517708672

173. Wang G, Marrie RA, Salter AR, et al. Health insurance affects the use of disease-modifying therapy in multiple sclerosis. Neurology. 2016;87(4):365-374. doi:10.1212/WNL.0000000000 002887

174. Freedman MS. "Time is brain" also in multiple sclerosis. Mult Scler. 2009;15(10):1133-1134. doi:10.1177/1352458509345920

175. Goodin DS, Reder AT, Ebers GC, et al. Survival in MS: a randomized cohort study 21 years after the start of the pivotal IFN $\beta-1 b$ trial. Neurology. 2012;78(17):1315-1322. doi:10.1212/ WNL.0b013e3182535cf6

176. Trojano M, Pellegrini F, Paolicelli D, et al. Real-life impact of early interferon $\beta$ therapy in relapsing multiple sclerosis. Ann Neurol. 2009;66(4):513-520. doi:10.1002/ana.21757

177. Gajofatto A, Benedetti MD. Treatment strategies for multiple sclerosis: when to start, when to change, when to stop? World J Clin Cases. 2015;3(7):545-555. doi:10.12998/wjcc.v3.i7.545

178. Bearak J, Popinchalk A, Alkema L, Sedgh G. Global, regional, and subregional trends in unintended pregnancy and its outcomes from 1990 to 2014: estimates from a Bayesian hierarchical model. Lancet Glob Health. 2018;6(4):e380-e389. doi:10.1016/S2214109X(18)30029-9

179. Finer LB, Zolna MR. Declines in unintended pregnancy in the United States, 2008- 2011. New Engl J Med. 2016;374 (9):843-852. doi:10.1056/NEJMsa1506575

180. Hutchinson M. Safety first, efficacy second in disease modifying therapies. Mult Scler. 2011;17(4):380-381. doi:10.1177/ 1352458511402114

181. Broadley SA, Barnett MH, Boggild $M$, et al. Therapeutic approaches to disease modifying therapy for multiple sclerosis in adults: an Australian and New Zealand perspective part 3 treatment practicalities and recommendations. J Clin Neurosci. 2014;21(11):1857-1865. doi:10.1016/j.jocn.2014.01.017

182. Miller DH, Fazekas F, Montalban X, Reingold SC, Trojano M. Pregnancy, sex and hormonal factors in multiple sclerosis. Mult Scler. 2014;20(5):527-536. doi:10.1177/1352458513519840

183. Thöne J, Thiel S, Gold R, Hellwig K. Treatment of multiple sclerosis during pregnancy-safety considerations. Expert Opin Drug Saf. 2017;16(5):523-534. doi:10.1080/14740338.2017.1311321

184. Houtchens MK, Edwards NC, Phillips AL. Relapses and disease-modifying drug treatment in pregnancy and live birth in US women with MS. Neurology. 2018;91(17):e1570-e1578. doi:10.1212/WNL.0000000000006382

185. Berenguer-Ruiz L, Gimenez-Martinez J, Palazón-Bru A, Sempere AP. Relapses and obstetric outcomes in women with multiple sclerosis planning pregnancy. J Neurol. 2019;266 (10):2512-2517. doi:10.1007/s00415-019-09450-6

186. Khalid F, Healy BC, Dupuy SL, et al. Quantitative MRI analysis of cerebral lesions and atrophy in post-partum patients with multiple sclerosis. J Neurol Sci. 2018;392:94-99. doi:10.1016/j. jns.2018.06.025

187. The European Medicines Agency - EMA. Aubagio. Summary of product characteristics. Available from: https://www.ema.europa. eu/en/documents/product-information/aubagio-epar-productinformation_en.pdf. Accessed August 2, 2021.

188. Sepúlveda $\bar{M}$, Montejo C, Llufriu S, et al. Rebound of multiple sclerosis activity after fingolimod withdrawal due to planning pregnancy: analysis of predisposing factors. Mult Scler Relat Disord. 2020;38:101483. doi:10.1016/j.msard.2019.101483
189. Barry B, Erwin AA, Stevens J, Tornatore C. Fingolimod rebound: a review of the clinical experience and management considerations. Neurol Ther. 2019;8(2):241-250. doi:10.1007/ s40120-019-00160-9

190. Meinl I, Havla J, Hohlfeld R, Kümpfel T. Recurrence of disease activity during pregnancy after cessation of fingolimod in multiple sclerosis. Mult Scler. 2018;24(7):991-994. doi:10.1177/ 1352458517731913

191. Novi G, Ghezzi A, Pizzorno M, et al. Dramatic rebounds of MS during pregnancy following fingolimod withdrawal. Neurol Neuroimmunol NeuroInflamm. 2017;4(5):e377. doi:10.1212/ NXI.0000000000000377

192. Sempere AP, Berenguer-Ruiz L, Feliu-Rey E. Rebound of disease activity during pregnancy after withdrawal of fingolimod. Eur $J$ Neurol. 2013;20(8):109-110. doi:10.1111/ene.12195

193. Litwin T, Smoliński $Ł$, Członkowka A. Substantial disease exacerbation in a patient with relapsing-remitting multiple sclerosis after withdrawal from siponimod. Neurol Neurochir Pol. 2018;52(1):98-101. doi:10.1016/j.pjnns.2017.10.001

194. Lamb YN. Ozanimod: first Approval. Drugs. 2020;80 (8):841-848. doi:10.1007/s40265-020-01319-7

195. The European Medicines Agency - EMA. Zeposia. Summary of product characteristics. Available from: https://www.ema.europa. eu/en/documents/product-information/zeposia-epar-productinformation_en.pdf. Accessed August 2, 2021.

196. The European Medicines Agency - EMA. Tysabri. Summary of product characteristics. Available from: https://www.ema.europa. eu/en/documents/product-information/tysabri-epar-productinformation_en.pdf. Accessed August 2, 2021.

197. Food and Drug Administration- FDA. Tysabri (Natalizumab) prescribing information. Available from: https://www.accessdata. fda.gov/drugsatfda_docs/label/2012/125104s0576lbl.pdf. Accessed August 2, 2021.

198. de Giglio L, Gasperini C, Tortorella C, Trojano M, Pozzilli C. Natalizumab discontinuation and disease restart in pregnancy: a case series. Acta Neurol Scand. 2015;131(5):336-340. doi:10.1111/ane.12364

199. Razaz N, Piehl F, Frisell T, Langer-Gould AM, McKay KA, Fink K. Disease activity in pregnancy and postpartum in women with MS who suspended rituximab and natalizumab. Neurol Neuroimmunol Neuroinflamm. 2020;7(6):e903. doi:10.1212/ NXI.0000000000000903

200. Vukusic S, Durand-Dubief F, Benoit A, Marignier R, Frangoulis B, Confavreux C. Natalizumab for the prevention of post-partum relapses in women with multiple sclerosis. Mult Scler. 2015;21(7):953-955. doi:10.1177/1352458514554056

201. Kleerekooper I, van Kempen ZLE, Leurs CE, et al. Disease activity following pregnancy-related discontinuation of natalizumab in MS. Neurol Neuroimmunol NeuroInflamm. 2017;5(1): e424. doi:10.1212/NXI.0000000000000424

202. Muller I, Moran C, Lecumberri B, et al. 2019 European Thyroid Association Guidelines on the management of thyroid dysfunction following immune reconstitution therapy. Eur Thyroid $J$. 2019;8(4):173-185. doi:10.1159/000500881

203. Oh J, Achiron A, Celius EG, et al. Pregnancy outcomes and postpartum relapse rates in women with RRMS treated with alemtuzumab in the Phase 2 and 3 clinical development program over 16 years. Mult Scler Relat Disord. 2020;43:102146. doi:10.1016/j.msard.2020.102146

204. Yalcin SE, Yalcin Y, Akkurt MO, Sezik M. Maternal and perinatal outcomes in pregnancies with multiple sclerosis: a case-control study. J Perinatal Med. 2017;45(4):455-460. doi:10.1515/jpm2016-0060 
205. Dobson R, Dassan P, Roberts M, Giovannoni G, Nelson-Piercy C, Brex PA. UK consensus on pregnancy in multiple sclerosis: "Association of British Neurologists" guidelines. Pract Neurol. 2019;19(2):106-114. doi:10.1136/practneurol-2018-002060

206. Palacios C, Kostiuk LK, Peña-Rosas JP. Vitamin D supplementation for women during pregnancy. Cochrane Database Syst Rev. 2019;7(7):CD008873. doi:10.1002/ 14651858.CD008873.pub4

207. Traboulsee A, Simon JH, Stone L, et al. Revised recommendations of the consortium of MS centers task force for a standardized MRI protocol and clinical guidelines for the diagnosis and follow-up of multiple sclerosis. AJNR Am $J$ Neuroradiol. 2016;37(3):394-401. doi:10.3174/ajnr.A4539

208. Ray JG, Vermeulen MJ, Bharatha A, Montanera WJ, Park AL. Association between MRI exposure during pregnancy and fetal and childhood outcomes. JAMA. 2016;316(9):952-961. doi:10.1001/jama.2016.12126

209. Lum M, Tsiouris AJ. MRI safety considerations during pregnancy. Clin Imaging. 2020;62:69-75. doi:10.1016/j. clinimag.2020.02.007

210. Mervak BM, Altun E, McGinty KA, Hyslop WB, Semelka RC, Burke LM. MRI in pregnancy: indications and practical considerations. J Magn Reson Imaging. 2019;49(3):621-631. doi:10.1002/jmri.26317

211. Haghikia A, Langer-Gould A, Rellensmann G, et al. Natalizumab use during the third trimester of pregnancy. JAMA Neurol. 2014;71(7):891-895. doi:10.1001/jamaneurol.2014.209

212. Triplett JD, Vijayan S, Rajanayagam S, Tuch P, Kermode AG. Pregnancy outcomes amongst multiple sclerosis females with third trimester natalizumab use. Mult Scler Relat Disord. 2020;40:101961. doi:10.1016/j.msard.2020.101961

213. Guilloton L, Pegat A, Defrance J, Quesnel L, Barral G, Drouet A. Neonatal pancytopenia in a child, born after maternal exposure to natalizumab throughout pregnancy. $J$ Gynecol Obstet Hum Reprod. 2017;46(3):301-302. doi:10.1016/j.jogoh.2017.02.008

214. Dobson R, Hellwig K. Use of disease-modifying drugs during pregnancy and breastfeeding. Curr Opin Neurol. 2021;34 (3):303-311. doi:10.1097/WCO.0000000000000922

215. Bomprezzi R, Pawate S. Extended interval dosing of natalizumab: a two-center, 7-year experience. Ther Adv Neurol Disord. 2014;7 (5):227-231. doi:10.1177/1756285614540224

216. Riancho J, Setien S, Sánchez de la Torre JR, et al. Does extended interval dosing natalizumab preserve effectiveness in multiple sclerosis? A 7 year-retrospective observational study. Front Immunol. 2021;12:614715. doi:10.3389/fimmu.2021.614715

217. Zhovtis Ryerson L, Frohman TC, Foley J, et al. Extended interval dosing of natalizumab in multiple sclerosis. $J$ Neurol Neurosurg Psychiatry. 2016;87(8):885-889. doi:10.1136/jnnp-2015-312940

218. Yamout BI, Sahraian MA, Ayoubi NE. Efficacy and safety of natalizumab extended interval dosing. Mult Scler Relat Disord. 2018;24:113-116. doi:10.1016/j.msard.2018.06.015

219. Norberg H, Stålnacke J, Heijtz RD, et al. Antenatal corticosteroids for preterm birth: dose-dependent reduction in birthweight, length and head circumference. Acta Paediatr. 2011;100 (3):364-369. doi:10.1111/j.1651-2227.2010.02074.x

220. Carmichael SL, Shaw GM, Ma C, et al. Maternal corticosteroid use and orofacial clefts. Am J Obstet Gynecol. 2007;197(6):585. e1-7. doi:10.1016/j.ajog.2007.05.046

221. Park-Wyllie L, Mazzotta P, Pastuszak A, et al. Birth defects after maternal exposure to corticosteroids: prospective cohort study and meta-analysis of epidemiological studies. Teratology. 2000;62(6):385-392. doi:10.1002/1096-9926(200012)62:6<385:: AID-TERA5 $>3.0 . \mathrm{CO} ; 2-\mathrm{Z}$

222. Skuladottir H, Wilcox AJ, Ma C, et al. Corticosteroid use and risk of orofacial clefts. Birth Defects Res A Clin Mol Teratol. 2014;100(6):499-506. doi:10.1002/bdra.23248
223. Bandoli G, Palmsten K, Forbess Smith CJ, Chambers CD. A review of systemic corticosteroid use in pregnancy and the risk of select pregnancy and birth outcomes. Rheum Dis Clin North Am. 2017;43(3):489-502. doi:10.1016/j.rdc.2017.04.013

224. Räikkönen K, Gissler M, Kajantie E. Associations between maternal antenatal corticosteroid treatment and mental and behavioral disorders in children. JAMA. 2020;323(19):1924-1933. doi:10.1001/jama.2020.3937

225. Houtchens MK, Kolb CM. Multiple sclerosis and pregnancy: therapeutic considerations. J Neurol. 2013;260(5):1202-1214. doi:10.1007/s00415-012-6653-9

226. Fragoso YD, Adoni T, Brooks JBB, et al. Practical evidence-based recommendations for patients with multiple sclerosis who want to have children. Neurol Ther. 2018;7 (2):207-232. doi:10.1007/s40120-018-0110-3

227. Rolfes L, Pfeuffer S, Ruck T, et al. Therapeutic apheresis in acute relapsing multiple sclerosis: current evidence and unmet needs- $\mathrm{A}$ systematic review. J Clin Med. 2019;8(10):1623. doi:10.3390/ jcm8101623

228. Reyes S, Ramsay M, Ladhani S, et al. Protecting people with multiple sclerosis through vaccination. Pract Neurol. 2020;20 (6):435-445. doi:10.1136/practneurol-2020-002527

229. Otero-Romero S, Rodríguez-García J, Vilella A, et al. Recommendations for vaccination in patients with multiple sclerosis who are eligible for immunosuppressive therapies: Spanish consensus statement. Neurologia (Engl Ed). 2021;36 (1):50-60. doi:10.1016/j.nrl.2020.02.006

230. Shimabukuro TT, Kim SY, Myers TR, et al. Preliminary findings of mRNA Covid-19 vaccine safety in pregnant persons. $N$ Engl $J$ Med. 2021;384(24):2273-2282. doi:10.1056/ NEJMoa2104983

231. Acog.org (homepage on the Internet). American College of Obstetricians and Gynecologists. COVID-19 Vaccination Considerations for Obstetric-Gynecologic Care. [updated July 30, 2021]. Available from: https://www.acog.org/clinical/ clinical-guidance/practice-advisory/articles/2020/12/covid-19vaccination-considerations-for-obstetric-gynecologic-care. Accessed December 22, 2021.

232. Canada.ca (homepage on the Internet). National Advisory Committee on Immunization. Public Health Agency of Canada. Recommendations on the use of COVID-19 Vaccines; July 22, 2021. Available from: https://www.canada.ca/en/pu blic-health/services/immunization/national-advisory-committeeon-immunization-naci/recommendations-use-covid-19-vaccines. html. Accessed December 22, 2021.

233. Australian Technical Advisory Group on Immunisation (ATAGI). Clinical guidance on use of COVID-19 vaccine in Australia in 2021. Version 6.0; July 30, 2021. Available from: https://www.health.gov.au/sites/default/files/documents/ 2021/08/covid-19-vaccination-atagi-clinical-guidance-on-covid -19-vaccine-in-australia-in-2021_0.pdf. Accessed August 2, 2021.

234. Limia Sanchez A, Navarro JA, Armona Aquerreta JM Vaccination working group in the adult population and risk groups of the Vaccination Program and Registry Report. Vaccination in risk groups of all ages and in certain situations. Public Health Commission of the Interterritorial Council of the National Health System. Ministry of Health, Consumption and Social Welfare, July 2018.: 137-145. Available from: http://www. ffis.es/ups/prl/vacunacion_grupos_riesgo.pdf. Accessed December 22, 2021.

235. Portaccio E, Ghezzi A, Hakiki B, et al. Postpartum relapses increase the risk of disability progression in multiple sclerosis: the role of disease modifying drugs. J Neurol Neurosurg Psychiatry. 2014;85(8):845-850. doi:10.1136/jnnp-2013306054 
236. Achiron A, Kishner I, Dolev M, et al. Effect of intravenous immunoglobulin treatment on pregnancy and postpartum- related relapses in multiple sclerosis. J Neurol. 2004;251:1133-1137. doi:10.1007/s00415-004-0495-z

237. Brandt-Wouters E, Gerlach OH, Hupperts RM. The effect of postpartum intravenous immunoglobulins on the relapse rate among patients with multiple sclerosis. Int $J$ Gynecol Obstet. 2016;134(2):194-196. doi:10.1016/j.ijgo.2016.01.008

238. Haas J, Hommes OR. A dose comparison study of IVIG in postpartum relapsing-remitting multiple sclerosis. Mult Scler. 2007;13(7):900-908. doi:10.1177/1352458506075654

239. Hellwig K, Beste C, Schimrigk S, Chan A. Immunomodulation and postpartum relapses in patients with multiple sclerosis. Ther Adv Neurol Disord. 2009;2(1):7-11. doi:10.1177/ 1756285608100416

240. Orvieto R, Achiron R, Rotstein Z, Noy S, Bar-Hava I, Achiron A. Pregnancy and multiple sclerosis: a 2-year experience. Eur $J$ Obstet Gynecol Reprod Biol. 1999;82(2):191-194. doi:10.1016/S0301-2115(98)00231-0

241. Fragoso YD, Adoni T, Alves-Leon SV, et al. Postpartum treatment with immunoglobulin does not prevent relapses of multiple sclerosis in the mother. Health Care Women Int. 2015;36 (10):1072-1080. doi:10.1080/07399332.2014.948627

242. Horvat Ledinek A, Brecl Jakob G, Jerše J, et al. Intravenous immunoglobulins for the prevention of postpartum relapses in multiple sclerosis. Mult Scler Related Disord. 2020;38:101519. doi:10.1016/j.msard.2019.101519

243. Rosa GR, O'Brien AT, Nogueira ED, Carvalho VM, Paz SC, Fragoso YD. There is no benefit in the use of postnatal intravenous immunoglobulin for the prevention of relapses of multiple sclerosis: findings from a systematic review and meta-analysis. Arq Neuropsiquiatr. 2018;76(6):361-366. doi:10.1590/0004282x20180041

244. de Seze J, Chapelotte M, Delalande S, Ferriby D, Stojkovic T, Vermersch P. Intravenous corticosteroids in the postpartum period for reduction of acute exacerbations in multiple sclerosis. Mult Scler. 2004;10(5):596-597. doi:10.1191/1352458504ms1079sr

245. Avila-Ornelas J, Avila M, Stosic M, et al. The role of postpartum intravenous corticosteroids in the prevention of relapses in multiple sclerosis. Int J MS Care. 2011;13:91-93. doi:10.7224/15372073-13.2.91

246. Durand-Dubief F, El-Etr M, Ionescu I, et al. The POPARTMUS French-Italian multicentric trial of postpartum progestin and estradiol in multiple sclerosis: MRI findings. Abstract (P063) at the ECTRIMS 2014 congress; September 10-13, 2014; Boston, USA. Available from: https://onlinelibrary.ectrims-congress.eu. Accessed December 22, 2021

247. Beaber BE, Chi MD, Brara MS, Zhang JL, Langer-Gould AM. Immunomodulatory agents and risk of postpartum multiple sclerosis relapses. Perm J. 2014;18(1):9-13. doi:10.7812/TPP/ 13-090

248. Portaccio E, Amato MP. Breastfeeding and post-partum relapses in multiple sclerosis patients. Mult Scler. 2019;25(9):1211-1216. doi:10.1177/1352458519830588

249. Krysko KM, Rutatangwa A, Graves J, Lazar A, Waubant E. Association between breastfeeding and postpartum multiple sclerosis relapses: a systematic review and meta-analysis. JAMA Neurol. 2020;77(3):327-338.

250. Langer-Gould A, Huang SM, Gupta R, et al. Exclusive breastfeeding and the risk of postpartum relapses in women with multiple sclerosis. Arch Neurol. 2009;66(8):958-963. doi:10.1001/ archneurol.2009.132

251. Victora CG, Bahl R, Barros AJD, et al. Breastfeeding in the 21st century: epidemiology, mechanisms, and lifelong effect. Lancet. 2016;387(10017):475-490. doi:10.1016/S0140-6736(15)01024-7
252. Dieterich CM, Felice JP, O'Sullivan E, Rasmussen KM. Breastfeeding and health outcomes for the mother-infant dyad. Pediatr Clin North Am. 2013;60(1):31-48. doi:10.1016/j. pcl.2012.09.010

253. Sattari M, Serwint JR, Levine DM. Maternal implications of breastfeeding: a review for the internist. Am J Med. 2019;132 (8):912-920. doi:10.1016/j.amjmed.2019.02.021

254. Almas S, Vance J, Baker T, Hale T. Management of multiple sclerosis in the breastfeeding mother. Multiple Scler Int. 2016;2016:6527458.

255. Hale TW, Siddiqui AA, Baker TE. Transfer of interferon $\beta$-1a into human breastmilk. Breastfeed Med. 2012;7(2):123-125. doi:10.1089/bfm.2011.0044

256. The European Medicines Agency - EMA. Rebif. Summary of product characteristics. Available from: https://www.ema.europa. $\mathrm{eu} /$ en/documents/product-information/rebif-epar-productinformation en.pdf. Accessed August 2, 2021.

257. Datta P, Ciplea AI, Rewers-Felkins K, et al. Cladribine transfer into human milk: a case report. Mult Scler. 2021;27(5):799-801. doi: $10.1177 / 1352458520912173$

258. Drugs and Lactation Database (LactMed) [Internet]. Ocrelizumab. Bethesda (MD): National Library of Medicine (US); 2006 [updated July 20, 2020]. https://www.ncbi.nlm.nih.gov/books/. Accessed December 22, 2021.

259. Proschmann U, Thomas K, Thiel S, Hellwig K, Ziemssen T. Natalizumab during pregnancy and lactation. Mult Scler. 2018;24(12):1627-1634. doi:10.1177/1352458517728813

260. LaHue SC, Anderson A, Krysko KM, et al. Transfer of monoclonal antibodies into breastmilk in neurologic and non-neurologic diseases. Neurol Neuroimmunol Neuroinflamm. 2020;7(4):e769. doi:10.1212/NXI.0000000000000769

261. Baker TE, Cooper SD, Kessler L, Hale TW. Transfer of natalizumab into breast milk in a mother with multiple sclerosis. J Hum Lact. 2015;31(2):233-236. doi:10.1177/0890334414566237

262. Ciplea AI, Langer-Gould A, de Vries A, et al. Monoclonal antibody treatment during pregnancy and/or lactation in women with MS or neuromyelitis optica spectrum disorder. Neurol Neuroimmunol Neuroinflamm. 2020;7(4):e723.

263. Tailor K, Bove R, Oreja-Guevara C, et al. Pregnancy outcomes in patients treated with ocrelizumab. ePoster (P1132) at the MSVirtual/Virtual 8th Joint ACTRIMS-ECTRIMS Meeting; September 11-13, 2020

264. Cooper SD, Felkins K, Baker TE, Hale TW. Transfer of methylprednisolone into breast milk in a mother with multiple sclerosis. $J \quad$ Hum Lact. 2015;31(2):237-239. doi:10.1177/ 0890334415570970

265. Kaplan TB. Management of demyelinating disorders in pregnancy. Neurol Clin. 2019;37(1):17-30. doi:10.1016/j. ncl.2018.09.007

266. Kraemer M, Weber R, Herold M, Berlit P. Reversible cerebral vasoconstriction syndrome associated with fingolimod treatment in relapsing-remitting multiple sclerosis three months after childbirth. Mult Scler. 2015;21(11):1473-1475. doi:10.1177/ 1352458515600249

267. Voskuhl R, Momtazee C. Pregnancy: effect on multiple sclerosis, treatment considerations, and breastfeeding. Neurotherapeutics. 2017;14(4):974-984.

268. ACOG Committee on Obstetric Practice. Committee Opinion No. 723: guidelines for diagnostic imaging during pregnancy and lactation. Obstet Gynecol. 2017;130(4):e210-e216. doi:10.1097/AOG.0000000000002355

269. Das G, Damotte V, Gelfand JM, et al. Rituximab before and during pregnancy: a systematic review, and a case series in MS and NMOSD. Neurol Neuroimmunol Neuroinflamm. 2018;5(3): e453. doi:10.1212/NXI.0000000000000453 
270. Chakravarty EF, Murray ER, Kelman A, Farmer P. Pregnancy outcomes after maternal exposure to rituximab. Blood. 2011;117 (5):1499-1506. doi:10.1182/blood-2010-07-295444

271. The European Medicines Agency - EMA. Kesimpta. Summary of product characteristics. Available from: https://www.ema.europa. eu/en/documents/product-information/kesimpta-epar-productinformation_en.pdf. Accessed November 20, 2021.
272. The European Medicines Agency - EMA. Ponvory. Summary of product characteristics. Available from: https:/www.ema.europa. eu/en/documents/product-information/ponvory-epar-productinformation_en.pdf. Accessed November 20, 2021.

\section{Publish your work in this journal}

Degenerative Neurological and Neuromuscular Disease is an international, peer-reviewed, open access journal focusing on research into degenerative neurological and neuromuscular disease, identification of therapeutic targets and the optimal use of preventative and integrated treatment interventions to achieve improved outcomes, enhanced survival and quality of life for the patient. The manuscript management system is completely online and includes a very quick and fair peer-review system. Visit http://www.dovepress.com/ testimonials.php to read real quotes from published authors.

Submit your manuscript here: http://www.dovepress.com/degenerative-neurological-and-neuromuscular-disease-journal 